\title{
1 A marine bacterial enzymatic cascade degrades the algal polysaccharide ulvan
}

2 Lukas Reisky, ${ }^{1 \#}$ Aurélie Préchoux, ${ }^{2 \#}$ Marie-Katherin Zühlke, ${ }^{3,4 \#}$ Marcus Bäumgen, ${ }^{1}$ Craig S.

3 Robb, ${ }^{5,6}$ Nadine Gerlach, ${ }^{5,6}$ Thomas Roret, ${ }^{7}$ Christian Stanetty, ${ }^{8}$ Robert Larocque, ${ }^{7}$ Gurvan

4 Michel, $^{2}$ Song Tao, ${ }^{5,6}$ Stephanie Markert,, ${ }^{3,4}$ Frank Unfried, ${ }^{3,4}$ Marko D. Mihovilovic, ${ }^{8}$ Anke

5 Trautwein-Schult, ${ }^{9}$ Dörte Becher, ${ }^{9}$ Thomas Schweder, ${ }^{3,4 *}$ Uwe T. Bornscheuer, ${ }^{1 *}$ Jan-Hendrik 6 Hehemann $n^{5,6 *}$

7

$8{ }^{1}$ Department of Biotechnology \& Enzyme Catalysis, Institute of Biochemistry, University 9 Greifswald, 17487 Greifswald, Germany

102 Sorbonne Université, CNRS, Integrative Biology of Marine Models (LBI2M), Station 11 Biologique de Roscoff (SBR), 29680 Roscoff, Bretagne, France

${ }^{3}$ Pharmaceutical Biotechnology, Institute of Pharmacy, University Greifswald, 17487 Greifswald, Germany

${ }^{4}$ Institute of Marine Biotechnology, 17489 Greifswald, Germany

${ }^{5}$ Max Planck-Institute for Marine Microbiology, 28359 Bremen, Germany

${ }^{6}$ University of Bremen, Center for Marine Environmental Sciences (MARUM), 28359 Bremen, Germany

7 Sorbonne Université, CNRS, FR 2424, Station Biologique de Roscoff (SBR), 29680 Roscoff, Bretagne, France

${ }^{8}$ Institute of Applied Synthetic Chemistry, TU Wien, 1060 Vienna, Austria

${ }^{9}$ Institute of Microbiology, University Greifswald, 17487 Greifswald, Germany

"These authors contributed equally to this work.

*To whom correspondence should be addressed. e-mail: schweder@uni-greifswald.de (TS);

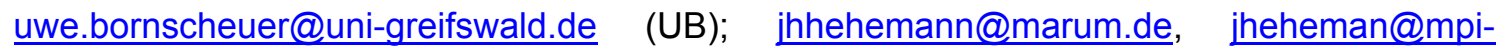
bremen.de $(\mathrm{JHH})$ 


\section{Abstract}

Marine seaweeds increasingly grow into extensive algal blooms, which are detrimental to coastal ecosystems, tourism, and aquaculture. However, algal biomass is also emerging as sustainable raw material for bioeconomy. The potential exploitation of algae is hindered by our limited knowledge of the microbial pathways - and hence the distinct biochemical functions of the enzymes involved - that convert algal polysaccharides into oligo- and monosaccharides. Understanding these processes would be essential, however, for applications like the fermentation of algal biomass into bioethanol or other value-added compounds. Here we describe the metabolic pathway that enables the marine flavobacterium Formosa agariphila to degrade ulvan, the major cell wall polysaccharide of bloom-forming Ulva species. The pathway involves 12 biochemically characterized carbohydrate-active enzymes, including two polysaccharide lyases, three sulfatases and seven glycoside hydrolases that sequentially break down ulvan into fermentable monosaccharides. This way, the enzymes turn a previously unexploited renewable into a valuable and ecologically sustainable bioresource.

\section{Introduction}

Algal photosynthesis provides half of the global primary production ${ }^{1}$. Carbon dioxide is converted into carbohydrates, which are polymerized into polysaccharides to store energy, build cell walls, and perform other biological functions. Algae are furthermore considered as a promising renewable carbon source, due to their competitive growth rates and unique cell walls. Unlike plants that are rich in woody tissue, comprising the insoluble polysaccharides cellulose and the aromatic polymer lignin, which increases recalcitrance against enzymatic digestion, algal cell walls are rich in gel-forming polysaccharides that are highly hydrated ${ }^{2}$. Hydration and the absence of lignin make harsh chemical and physical pretreatment of cell walls unnecessary, and allow for easy access of enzymes that can digest the 
polysaccharides into fermentable monosaccharides. Accordingly, recent studies showed that bioengineered microbes equipped with agarases and alginate lyases can efficiently digest and rapidly convert polysaccharides from brown and red algae into bioethanol ${ }^{3}$.

Sessile macroalgae, such as brown algae that form kelp forests, are ecologically valuable because they provide nutrition and habitats for fish and other organisms and, consequently, harvesting them would exacerbate pressure on natural populations. However, the planktonic macroalgae Ulva armoricana, Ulva rotunda and other Ulva spp. that thrive in eutrophic, nutrient-rich coastal waters, grow into expansive blooms that occur with increasing frequency in recent years. They pose ecological but also economical threats when they accumulate on beaches used for recreation ${ }^{4-6}$. Fertilized by nitrate from agriculture that is washed into the ocean by rivers, Ulva blooms during summer produce up to 50-100 000 tons of biomass every year, which must be removed at high expense from the northern and western coast of France $^{6}$. Even larger blooms occur in China ${ }^{5}$. Blooms of Ulva are thus a global phenomenon that is bound to increase with farming activities, rendering the polysaccharide ulvan, which accounts for up to $30 \%$ of the algal dry weight ${ }^{7}$, an emerging yet untapped resource.

Ulvan is a branched polysaccharide composed of repeating disaccharide units, in which Dglucuronic acid (GICA) is $\beta$-1,4-linked or L-iduronic acid (IdoA) is $\alpha-1,4$-linked to L-rhamnose3-sulfate (Rha3S), which is $\alpha-1,4-$ linked within the main chain. Some of the uronic acids are replaced by $\beta-1,4-$ linked D-xylose $(X y l)$, which can be sulfated at position 2 (Xyl2S). Furthermore, Rha3S can be modified by $\beta-1,2$-linked GlcA side chains and the GlcA-Rha3S or IdoA-Rha3S pattern can be interrupted by consecutive GICA residues ${ }^{7-9}$. Increased interest in the enzymatic degradation of ulvan recently led to the description of several ulvan-active enzymes $^{10-15}$. So far, and to the best of our knowledge, only two types of enzymes from different carbohydrate-active enzyme (CAZyme) families showed activity on ulvan. Ulvan polysaccharide lyases of the families PL24, PL25 and PL28 catalyze the initial cleavage between Rha3S and GlcA or IdoA, resulting in the formation of unsaturated uronic acid residues at the end of the formed oligosaccharide. Unsaturated uronic acid residues are 
removed by glycoside hydrolases $(\mathrm{GHs})$ from the family $\mathrm{GH} 105^{15,16}$. Ulvan-specific degradation-related gene loci ('polysaccharide utilization loci', PULs) such as PUL H from Formosa agariphila encode PL28 and GH105 together with over 10 additional, putative enzymes, which were predicted to be involved in ulvan utilization. While PL28 and GH105 degrade ulvan, the other enzymes that were produced in Escherichia coli did not show activity $^{15}$. This result suggested that a complex cascade of sequential enzymatic reactions is required for complete ulvan degradation ${ }^{15,17}$.

Here, we experimentally established the complex ulvan degradation pathway of $F$. agariphila $\mathrm{KMM} 3901^{\top}$, a marine flavobacterium, which was isolated from a green alga in the Sea of $\operatorname{Japan}^{18}$. These degradation-related enzymes are encoded in an ulvan-specific PUL in the bacterial genome ${ }^{15}$.

\section{Results}

\section{Bacterial ulvan-specific PULs}

To decipher the ulvan degradation pathway, we first searched microbial genomes hosted at NCBI for potential ulvan-specific PULs using the known ulvan lyase PL28 as query. We identified 12 putative ulvan PULs in 12 Bacteroidetes genomes (Fig. 1a), including the recently discovered PUL $H$ of $F$. agariphila ${ }^{15,18}$, a more than $75 \mathrm{~kb}$ long genomic region consisting of 39 genes (Fig. 1b). We verified the boundaries of PUL $\mathrm{H}$ with a comparative global proteome analysis of $F$. agariphila cells fed with ulvan and with control substrates (rhamnose and fructose), respectively, as sole carbon source. Ulvan promoted bacterial growth (Supplementary Fig. 1) and elicited quantitative changes of most proteins that are encoded by PUL H (Table 1, Fig. 1b, and Supplementary Fig. 2). Besides ulvan, also the monosaccharide rhamnose induced, albeit less strongly, the expression of PUL $\mathrm{H}$ genes. For a few proteins (P2_SusD, P3_TBDR, P8_GH2) even higher protein amounts were detected with rhamnose, compared to ulvan. The increased abundance of enzymes involved in the 
degradation of ulvan-derived monosaccharides indicated a co-regulation of genes for the metabolization of ulvan and its corresponding monosaccharides (Table 1, Supplementary Figs. 2 and 3, Supplementary Data Sets 1 and 2). PUL H includes 17 potential carbohydrateactive enzymes (CAZymes) from different $\mathrm{GH}$ and PL families (http://www.cazy.org/ ${ }^{19}$ ) and eight sulfatases from five S1 subfamilies (http://abims.sb-roscoff.fr/sulfatlas ${ }^{20}$ ). For most of these enzymes, their role in ulvan depolymerization remains unknown. A co-occurrence analysis of putative enzymes and associated genes within the set of 12 PULs from marine Bacteroidetes identified conserved CAZymes in the putative ulvan pathways (Fig. 1c). This analysis allowed us to focus our biochemical experiments on a smaller subset of CAZymes and sulfatases, whose involvement in ulvan utilization was suggested by our proteomic results (Fig. 1b).

In addition to the two already known ${ }^{15}$ ulvanolytic enzyme activities (ulvan lyase and unsaturated glucuronyl hydrolase, $\mathrm{GH} 105)$ we uncovered eight so far unknown enzyme functions for the complete depolymerization of ulvan. Besides a novel PL family, we identified and characterized six $\mathrm{GH}$ families $(\mathrm{GH} 2, \mathrm{GH} 3, \mathrm{GH} 39, \mathrm{GH} 43, \mathrm{GH} 78, \mathrm{GH} 88)$ and three sulfatases.

Activity-based screenings of these enzymes were used to identify their function in the ulvan degradation pathway. The selection of putative CAZymes and sulfatases for cloning, heterologous expression and characterization was guided by the co-occurrence analysis of genes in the diverse ulvan PULs (Fig. 1c).

\section{Sulfatases active on ulvan}

Ulvans feature a large structural variability, with substitution by sulfate esters at various positions. This chemical diversity is influenced by several factors such as the algal species, the environmental conditions or the seasons ${ }^{7}$. The studied PUL of $F$. agariphila encodes 8 formylglycine-dependent sulfatases belonging to 5 subfamilies of the SulfAtlas S1 family 
132 (Table 1): S1_7: 3 genes; S1_8: 2 genes; S1_16: 1 gene; S1_25: 1 gene; S1_27: 1 gene 133 (http://abims.sbroscoff.fr/sulfatlas $)^{20}$. With such a diversity of S1 subfamilies, these sulfatases 134 likely display significant differences in substrate recognition, even though they are all 135 predicted to act on ulvans. We expressed 7 sulfatases in soluble form in E. coli. After 136 purification, these recombinant sulfatases were incubated with ulvan polymers from three 137 different sources (Agrival, Elicityl, and one extracted from an Altantic Ulva sp. collected in 138 Roscoff, France). As shown by the HPAEC analyzes of released sulfate ions, 6 sulfatases 139 are clearly active on ulvan polymers, although their activity varies depending on the 140 polysaccharide sources (Supplementary Fig. 4). The sulfatase P18_S1_7 (for 141 numbering/nomenclature see Table 1) was most active on ulvan polymers, particularly on the 142 xylose-rich ulvan (Supplementary Figs. 4 and 5) and can desulfate oligosaccharides 143 containing the motif Rha3S-Xyl2S-Rha3S. Thus, this sulfatase likely proceeds in an endolytic 144 mode of action. This assumption is consistent with the "open groove" topology of the active 145 site unraveled by the P18_S1_7 crystal structure (Fig. 2a and 2g). Interestingly, P14_S1_7 146 (predicted as exolytic, since this sulfatase is almost inactive on ulvan, Supplementary Fig. 4) 147 and P18_S1_7 (predicted as endolytic) belong to the same subfamily (S1_7). Such dissimilar 148 modes of action within the same (sub)family have been described in glycoside hydrolase and 149 polysaccharide lyase families ${ }^{21,22}$.In comparison to P18_S1_7, the S1_25 sulfatase module 150 of P36 (referred to as P36_S1_25) presents moderate activities on polymers. On 151 oligosaccharides, P36_S1_25 was the most active enzyme. This enzyme specifically 152 desulfates L-rhamnose at the 3-position and can act on the motif Rha3S-Xyl-Rha3S in an 153 exolytic mode of action.

154 Sequence analyses revealed that P18_S1_7 (485 residues) and the S1_25 sulfatase module 155 of P36_S1_25 (443 residues) are only distantly related (25\% identity) and thus belong to two 156 different SulfAtlas S1 subfamilies $^{20}, \mathrm{~S} 1 \_7$ and S1_25, respectively. We determined the 157 crystal structure of these two sulfatases, with higher resolution for P18_S1_7 (1.23 $\AA$ ) and 158 lower resolution for the sulfatase module of P36_S1_25 (2.91 Å). P18_S1_7 and P36_S1_25 159 adopt a similar fold with two $\alpha / \beta$-structural domains, an $N$-terminal catalytic domain SD1 
160

161

162

163

164

165

166

167

168

169

170

171

172

173

174

175

176

177

178

179

180

181

182

183

184

185

186

187

(Ser25-Asp388; P18_S1_7) separated by a structured linker (Arg389-Val397) from a Cterminal domain SD2 (Ala398-Pro483). Nonetheless, the sulfatase module of P36_S1_25 is a smaller protein and lacks some secondary elements, which are present in P18_S1_7 (the $\beta$-strands $\beta 6$ and $\beta 8$, the $\alpha$-helices $\alpha 5, \alpha 7, \alpha 8$ and several short $3: 10$ helices). Notably, the helix $\alpha 7$ and the loops connecting it to the main part of SD1 constitute a protruding extension, which overhangs the active site (Fig. 2d). The active site of P18_S1_7 is a large, open groove with a strong basic character (Fig. 2a and $2 \mathrm{~g}$ ). This type of active site topology is consistent with the endo-character and its efficiency on polymeric ulvan (Supplementary Fig. 4). In contrast, the active site of P36_S1_25 is a pocket (Fig. 2c), which is consistent with its activity on oligosaccharides (Supplementary Fig. 4). The most similar protein in the Protein Data Bank (PDB) is the human iduronate 2-sulfatase (IDS, 31\% sequence identity; PDB: 5FQL; Fig. $2 \mathrm{~b}$ and $2 \mathrm{e})^{23}$. Interestingly, IDS also displays a pocket active site topology (Fig. $2 b$ ). Therefore, different active sites (and subsequently different modes of action) can exist within the same S1 subfamily. Such differences in topology likely explain the varying efficiencies at the polymer level observed for P11_S1_7, P14_S1_7 and P18_S1_7 although they all belong to the S1_7 subfamily (Supplementary Fig. 4).

The catalytic machinery of the $\mathrm{S} 1$ family sulfatases ${ }^{24}$ is well conserved in P18_S1_7 and P36_S1_25. We find the catalytic nucleophile (Cys74 and Cys58, respectively), residues involved in $\mathrm{Ca}^{2+}$ coordination (Asp35, Asp36, Asp312 and His313; Asp18, Asp19, Asp284 and Asn285), residues stabilizing the catalytic nucleophile (Arg78 and His128; Arg62 and Gly110), and residues of the sulfate-binding S subsite, as defined in the recent nomenclature for sulfatase-binding subsites ${ }^{25}$ (Lys125, His213 and Lys325; Lys108, His182 and Lys297) (Fig. 2g, Supplementary Figs. 6-8). His313 in P18_S1_7 is not the most frequent residue for the coordination of the calcium ion (usually an asparagine), but a histidine at this position is found in a minority of sulfatases and is part of the updated PROSITE signature "Calciumbinding site ${ }^{200}$. Most surprising is the replacement of His128 in P18_S1_7 by Gly100 in the sulfatase module of P36_S1_25. Indeed, a histidine at this position is supposed not only to stabilize the catalytic formylglycine, but also to abstract its Oy2 proton at the end of the 
188

189

190

191

192

193

194

195

196

197

198

199

200

201

202

203

204

205

206

207

208

209

210

211

212

213

214

catalytic cycle to induce the sulfate elimination and the aldehyde regeneration ${ }^{24}$. Nonetheless, this glycine is strictly conserved in the closest homologs of the sulfatase module of P36_S1_25 (105 sequences with $>50 \%$ identity; Supplementary Fig. 7), suggesting that the function of the histidine at this position may not be essential in this ulvan sulfatase subgroup.

While some sulfatases were not quantified in our metabolic labeling approach (Fig. 1b, Table 1), they were detected by subproteome analysis in the membrane-enriched fraction. In five cases, lipoprotein signal peptides were predicted and P18_S1_7 and P36_S1_25 were highly abundant in the intracellular soluble fraction (Supplementary Data Set 3). Taken together, these results indicate a periplasmic localization of sulfatases, with some of them putatively membrane-bound. Notably, the sulfatase P36_S1_25 activity is found in a multimodular enzyme that contains also a GH78 domain. Comparative genome analyses indicated multimodular enzyme structures in the ulvan PUL $\mathrm{H}$ of $F$. agariphila ${ }^{15}$ and other putative ulvan-degrading Bacteroidetes strains (Supplementary Data Set 4).

\section{Enzymatic ulvan degradation}

In brief, the distinct function of each enzyme was established by activity testing on ulvan and on defined enzymatically produced ulvan oligomers using photometric assays, fluorophoreassisted carbohydrate electrophoresis (FACE) and carbohydrate polyacrylamide gel electrophoresis (C-PAGE), high performance anionic exchange chromatography with pulsed amperometric detection (HPAEC-PAD) and mass-spectrometry. Detailed procedures of these steps are outlined in the Online Methods section. Structures of all important carbohydrate intermediates were confirmed by $1 \mathrm{D}$ and 2D nuclear magnetic resonance (NMR) spectroscopy together with mass-spectrometry analysis.

We performed an initial photometric screening, which detects the unsaturated uronic acid moiety $(\Delta)$ introduced by the lytic mechanism of lyases. We show that P10_PLnc and P30_PL28 are both endo-acting ulvan lyases generating the same product pattern, implying 
215 that they have a similar specificity (Supplementary Fig. 9). P30_PL28 accepts GlcA and IdoA

216 at the cleavage site and generates the dimer $\Delta$-Rha3S and the tetramer $\Delta$-Rha3S-Xyl-Rha3S

217 as main products ${ }^{14}$. Both ulvan lyases, P30_PL28 ${ }^{26}$ and P10_PLnc, appear to initiate ulvan

218 depolymerization outside of the bacterial cell. P30_PL28 contains an additional ulvan-binding

219 module $^{13}$ and a type IX secretion system signal that drives secretion ${ }^{27}$, corroborating the

220 proteomic results (Supplementary Fig. 10, Supplementary Data Sets 2 and 3). P10_PLnc

221 might be associated to the outer membrane (Supplementary Data Set 3), although a

222 periplasmic localization is also possible (Supplementary Fig. 10, Supplementary Data Set 2).

223 Two variants of ulvan lyase with distinct localizations indicate synergistic functions: while 224 P30_PL28 is an extracellular enzyme catalyzing rapid dissolution of insoluble ulvan, 225 P10_PLnc most likely dissolves soluble ulvan oligomers at the cell surface, where uptake 226 proceeds through the expressed TonB-dependent receptor system into the periplasm. Here, 227 the unsaturated uronyl residue $(\Delta)$ at the non-reducing end of oligomers is removed by the 228 exo-acting unsaturated glucuronyl hydrolases (outer membrane P1_GH88 and periplasmic 229 P33_GH105) (Supplementary Figs. 11-13), thus forming 5-dehydro-4-deoxy-D-glucuronate. 230 The resulting Rha3S was purified and the structure was confirmed by NMR (Supplementary 231 Figs. 14 and 15, Supplementary Table 1). This monosaccharide is desulfated by the S1_25 232 sulfatase domain of P36_S1_25 yielding rhamnose, which can enter the cellular sugar 233 metabolism (Fig. 3, Supplementary Fig. 16). Rha3S-Xyl-Rha3S was another major 234 intermediate which was isolated (Supplementary Figs. 17 and 18, Supplementary Table 2). 235 Rha3S-Xyl-Rha3S was desulfated by the sulfatase P36_S1_25 to yield Rha-Xyl-Rha3S, 236 which was isolated to confirm the desulfation site at the non-reducing end (Supplementary 237 Figs. 19-21, Supplementary Table 3). Next, Rha-Xyl-Rha3S is converted by the periplasmic 238 P20_GH78 to Rha and Xyl-Rha3S (Fig. 3, Supplementary Fig. 22). The CBM67 domain of 239 P20_GH78 likely elevates specificity for rhamnose and contributes to substrate recognition ${ }^{28}$. 240 Finally, the dimer Xyl-Rha3S is further cleaved by P24_GH3 or P27_GH43 to yield Xyl and 241 Rha3S, making these the first identified $\beta$-xylosidases that are active on ulvan 242 oligosaccharides (Fig. 3, Supplementary Figs. 22 and 23). Notably, only the P24_GH3 was 
243 previously found to be active on 4-methylumbelliferyl- $\beta$-D-xylopyranoside (MUX) showing that 244 the two enzymes have different substrate specificity at the aglycone site $^{15}$.

245 Besides ulvan lyases, the endo-active alpha-1,4-L-rhamnosidase GH39 cleaves rhamnose 246 sections interspersed between xylose residues within the polymer. Such a function has, to 247 the best of our knowledge, not been described in this family before. Accordingly, larger 248 oligomers with consecutive Xyl-Rha3S units that are resistant to the ulvan lyases P30_PL28 249 and P10_PLnc were efficiently degraded by P31_GH39 (Supplementary Fig. 24). The 250 catalytic order of ulvan lyases and P31_GH39 was interchangeable as the larger degradation 251 products of P31_GH39 were prime substrates for both ulvan lyases (Supplementary Fig. 25). 252 The dimers Xyl-Rha3S and Xyl2S-Rha3S were isolated as the smallest products and the 253 structure was elucidated by NMR, identifying GH39 as an a-rhamnosidase active on ulvan 254 (Supplementary Figs. 26-29, Supplementary Tables 4 and 5). While Xyl-Rha3S is further 255 degraded as described above, Xyl2S-Rha3S was resistant to P24_GH3 or P27_GH43 and 256 needs to be desulfated by the P32_S1_8 sulfatase prior to enzymatic conversion by these 257 enzymes (Supplementary Fig. 30). Desulfation of Xyl2S within the trimer Rha3S-Xyl2S258 Rha3S, released by P30_PL28 and P33_105 digestion (Supplementary Figs. 31 and 32, 259 Supplementary Table 6), was catalyzed by the P18_S1_7 sulfatase (Supplementary Fig. 33).

260 GlcA side chains present on some $\mathrm{O} 2$ residues of $\mathrm{Rha3S}^{7}$ are removed by $\mathrm{P} 17$ GH 2 . When 261 P17_GH2 was added to untreated ulvan, it produced a single band in FACE with the same 262 mobility as a GlcA (Supplementary Fig. 34a) while not decreasing the overall molecular 263 weight of the raw ulvan as seen by C-PAGE (Supplementary Fig. 9). To confirm this activity, 264 defined oligomers with GlcA side chains were produced from ulvan with P30_PL28 and 265 P31_GH39 with or without P33_GH105. The structure of $\Delta$-Rha3S[2GlcA]-Xyl-Rha3S and 266 Rha3S[2GlcA]-Xyl-Rha3S, was confirmed by NMR (Supplementary Figs. 35-38, 267 Supplementary Tables 7 and 8 ) and these products were used as substrates for P17_GH2. 268 This enzyme was also active on these smaller oligomers (Fig. 3, Supplementary Fig. 34b). 269 This result indicates that the GlcA side chains were removed from polymeric ulvan or from 
smaller intermediates (Supplementary Fig. 34c), although in F. agariphila we predict

271 P17_GH2 to be localized in the periplasm and thus to be active on oligomers, which also 272 applies to P31_GH39.

273 GlcA side chains partially shielded the main chain against hydrolysis by P31_GH39. When 274 the GlcA residues were removed by $\mathrm{P} 17 \_\mathrm{GH} 2$, a higher degree of degradation was observed 275 with P31_GH39 (Supplementary Fig. 39). The newly determined crystal structure of 276 P17_GH2 (Supplementary Fig. 40) contains a pair of $N$-terminal $\beta$-sandwich domains, a TIM277 barrel with the active site, two more $\beta$-sandwich domains and a $C$-terminal putative 278 carbohydrate-binding module connected by an extended flexible linker at the $C$-terminus that 279 places the CBM over the active site (Supplementary Fig. 40a). The active site pocket is at 280 the surface of the catalytic domain; its size provides just enough space to accommodate one 281 GlcA residue. The catalytic site of this enzyme, obscured by the aforementioned CBM, 282 further deviates from other members of the $\mathrm{GH} 2$ family. In most $\mathrm{GH} 2$ the nucleophile and $283 \mathrm{acid} /$ base catalytic residues are approximately 200 residues apart at the $C$-terminal ends of 284 strands 4 and 7 of the conserved $(\alpha / \beta)_{8}$-TIM barrel fold. In P17_GH2, the nucleophile is 285 conserved (Glu509) but the acid/base position has a tryptophan (Trp447) (Supplementary Fig. 40d). Two alternative possibilities exist for the acid/base of P17_GH2 Glu411 found on strand 3 and Asp908 from the C-terminal domain (CTD) are both approximately $6.8 \AA$ from

288 Glu509 and could contribute to catalyzing hydrolysis as acid/base residues (Supplementary 289 Fig. 40c).

\section{Monosaccharide metabolism}

Ulvan degradation releases different monosaccharides to be further utilized by $F$. agariphila. Many of the enzymes involved in monosaccharide metabolism had significantly higher 293 relative abundances with ulvan compared to fructose or rhamnose as substrate (Table 1, 294 Supplementary Fig. 3, Supplementary Data Set 1). Based on this result and on the MetaCyc 295 database $\mathrm{e}^{29}$, pathways for monosaccharide utilization were deduced, which are consistent 
proteins, these monosaccharide-utilizing proteins are randomly distributed across the $F$. 298 agariphila genome (Supplementary Fig. 3).

299 The spontaneous conversion of $\alpha$ - to $\beta$-anomer (mutarotation) of free $\alpha$-L-rhamnose is a 300 relatively slow process. This rate-limiting step affects growth of L-rhamnose-utilizing 301 bacteria $^{30,31}$ because the first metabolic enzyme rhamnose isomerase (EC 5.3.1.14) is 302 specific for the $\beta$-anomer ${ }^{32}$. Various bacteria, such as E. coli and Rhizobium leguminosarum, 303 contain the L-rhamnose mutarotase, accelerating the rate of mutarotation of $\alpha$ - to $\beta$-L304 rhamnose ${ }^{37,38}$. In contrast to the proteobacterial L-rhamnose mutarotase genes, which are 305 part of small operons dedicated to the uptake and use of free L-rhamnose ${ }^{30,31}$, the 306 P21_mutarotase gene is localized in PUL $H$. We solved the crystal structure of the 307 P21_mutarotase at $1.47 \AA$ (Fig. 4, Supplementary Table 9) with one molecule in the 308 asymmetric unit. P21_mutarotase adopts a ferredoxin-like fold with an antiparallel $\beta$-sheet of

$3094 \beta$-strands flanked by a bundle of $3 \alpha$-helices. The P21_mutarotase structure superimposed 310 with the characterized L-rhamnose mutarotases YiiL (PDB: 1x8d) and RhaU (PDB: 2qlw) with $311 \mathrm{rmsd}$ on $\mathrm{C}_{\alpha}$ of $0.76 \AA$ and $0.73 \AA$, respectively ${ }^{30,31}$. Similar to these, the P21_mutarotase (Fig. $3124 a$ and $4 b)$ formed a dimer with a large hydrophobic dimeric interface antiparallel $\beta$-sheets 313 from each monomer (Fig. 4c). All key residues of the active site are well conserved in the 314 P21_mutarotase (Fig. 4d and 4e).

$315 F$. agariphila further metabolizes the $\beta$-L-rhamnose via L-rhamnulose-1-phosphate, which is 316 then cleaved by an aldolase (putatively NP3_ or/and NP6_aldolase, Table 1) into L317 lactaldehyde and dihydroxyacetone phosphate (Fig. 5) ${ }^{15}$. The corresponding genes are 318 located directly upstream of PUL H (Supplementary Figs. 2 and 3). Glucuronic and 319 unsaturated uronic acids are stepwise converted into KDG (2-dehydro-3-deoxy-D-gluconate), 320 which enters the central metabolism via D-glyceraldehyde 3-phosphate and pyruvate (Fig. 5). 321 Corresponding genes are encoded within PUL $H$, PUL $A$ or elsewhere in the genome 322 (Supplementary Figs. 3 and 41). NP8_isomerase and NP7_kinase convert D-xylose to D323 xylulose-5P, which is an intermediate of the pentose phosphate pathway. In addition, 324 putative monosaccharide transporters were identified (Fig. 5). A D-xylose transporter 
(NP16_XylE) was quantified in the membrane fraction in the subproteome experiments (Supplementary Data Set 2). Four ATP-binding proteins of ABC transporters were more abundant with ulvan or with rhamnose in the metabolic labeling experiments (Table 1, Supplementary Data Set 1), indicating that ABC-transporters are involved in monosaccharide uptake. Specific mono- or oligosaccharides generated by the above described enzymatic steps were also verified by HPLC-ELS-ESI-MS (Supplementary Figs. 42-48).

\section{Discussion}

Using the DNA sequence of the known ulvan polysaccharide lyase PL28 as query, 12 ulvan

334 PULs were extracted from the NCBI-GenBank, including the biochemically characterized $F$. agariphila ulvan PUL. All PULs were from Bacteroidetes, indicating that our procedure was selective for this phylum since ulvan PULs also exist in Gammaproteobacteria ${ }^{33}$. Interestingly, although four ulvan PULs were from the genus Polaribacter, they did not cluster on the heatmap (Figure 1c) indicating that ulvan PULs are diverse at the genus level. Also, within different ulvan PULs, PL28 or PLs from PLnc are over $50 \%$ identical at the pairwise amino acid sequence level. Conservation and invariable presence suggest that the first steps of the ulvan degradation cascade proceed through similar enzymes in these organisms. On the other hand, the GH88 enzyme was only present in ulvan PULs of Flammeovirga pacifica and $F$. agariphila. GH88 is an exo-acting, unsaturated glucuronyl hydrolase. Its absence in other ulvan PULs could be compensated for by the presence of a $\mathrm{GH} 105$, which has the same function. Thus, the later steps in ulvan degradation proceed in dissimilar ways in bacteria.

As shown in the protein domain distribution analysis, the most abundant proteins are sulfatases, which catalyze the removal of sulfate from ulvan. Sulfatase copy numbers ranged from 4-12. At the same time, PLs or GHs such as GH2, GH78 and GH39 in the F. agariphila ulvan PUL were also abundant and have several copies in the other predicted ulvan PULs. Notably, some of the proteins of the ulvan PUL, such as the sulfatase P36_GH78/S1_25, are 
multimodular enzymes. Our analyses indicated similar domain structures of ulvan-degrading enzymes in other marine Bacteroidetes strains. However, the cursory inspection of gut Bacteroides genomes revealed no multimodular $\mathrm{GH} 78$ and sulfatase fusion proteins. This suggests that some gene fusions involved in polysaccharide degradation could be more abundant in the marine environment ${ }^{34}$.

Our biochemical analyses demonstrated that six of the putative sulfatases (P11_S1_7, P12_S1_8, P18_S1_7, P19_S1_27, P32_S1_8 and P36_S1_25) are ulvan-active indeed sulfatases (Supplementary Fig. 4). However, the sulfatase P14_S1_7 was inactive on both, ulvan from Elicityl and a xylose-rich ulvan from Atlantic Ulva spp. and displayed only faint activity on an ulvan from Agrival. This apparent inactivity may be due to a strict exolytic character of P14_S1_7. Consequently, activity maxima are not the same for different types of ulvans. Substrate diversity may cause the variable enzyme content in Bacteroidetes (Figure 1c). This diversity may reflect an adaptation to the different types of ulvans present in Ulva spp. Such fine scale adaptation points towards the exploration of PUL microdiversity as a promising avenue for enzyme discovery and for the biocatalytic elucidation of ulvan structures.

Our elucidation of the enzymatic ulvan degradation cascade and characterization of 12 of its enzymes has major implications. Firstly, the conservation of CAZyme- and sulfataseencoding genes in ulvan PULs of different bacteria underlines their importance and provides a mean to reliably predict new ulvan degradation pathways for bioengineering. Secondly, the

372 substantially extended knowledge of the specific substrate scope of each enzyme enables 373 the targeted use of these enzymes for the production of a variety of novel defined, tailor374 made ulvan oligomers, representing useful products, e.g., for pharmaceutical or cosmetic 375 applications. Moreover, these enzymes provide a way to deconstruct ulvan cell walls, which 376 may facilitate the extraction of marine poly- or oligosaccharides and other valuable molecules

377 such as proteins from Ulva spp. Finally, the enzymatic cascade allows for the production of 
bulk monomeric sugars from the abundant, so far underexplored renewable, the green tide Ulva.

\section{Acknowledgements}

We thank the German Research Foundation (DFG) for funding through the Research Unit FOR2406 "Proteogenomics of Marine Polysaccharide Utilization" (POMPU) (by grants of U.T.B. (BO 1862/17-1), J.-H.H. (HE 7217/2-1), and T.S. (SCHW 595/10-1). J.-H.H. acknowledges funding by the Emmy-Noether-Program of the DFG, grant number HE 7217/11. G.M. is grateful to the French National Research Agency (ANR) for its support with regards to the investment expenditure program IDEALG (grant number ANR-10-BTBR-04) and the Blue Enzymes project (reference ANR-14-CE19-0020-01). M.-K.Z. and F.U. were supported by scholarships from the Institute of Marine Biotechnology e.V. We thank Cédric Leroux for mass spectrometry analyses and Mirjam Czjzek and Alisdair Boraston for helpful discussions. We are indebted to the local contacts for their support during X-ray data collection at the PROXIMA-1 and PROXIMA-2 beamlines (SOLEIL Synchrotron, Saint Aubin, France) and the P11 beamline (DESY, Hamburg, Germany). We thank Andreas Otto and Sabryna Junker for help with the metabolic labeling approach and Tjorven Hinzke for support with analyses of the proteome data. We thank Dr. Frédéric Lesourd (Agrival, Plouenan, France) for the gift of the "Agrival" ulvan sample.

\section{Author contributions}

J.-H.H., T.S., G.M. and U.T.B. initiated the study and directed the project. L.R., A.P., R.L. and M.B. cloned the genes and expressed and purified the enzymes for the degradation reactions. M.B., J.-H.H. and L.R. isolated ulvan and purified oligomers. Metabolites were analyzed by C.S. via NMR and HPLC-ELS-MS for which M.D.M. provided resources. L.R. and M.B. performed biocatalysis for the analyses in gel-based assays whereas A.P. together 
with M.B. performed HPAEC-PAD analyses. M.-K.Z. with support from S.M., F.U. and A.T.-S. performed the proteome analyses for which D.B. provided the resources. N.G., C.S.R. and T.R. performed crystallographic experiments and solved the protein structures. G.M. analyzed the crystal structure of the L-rhamnose mutarotase and of the sulfatases. S.T. performed the computational analyses of PUL predictions. J.-H.H. and L.R. wrote the paper with input from U.T.B., G.M., S.M., M.-K.Z. and T.S. All authors read and approved the final manuscript and declare that there is no conflict of interest.

\section{Competing financial interests}

The authors declare no conflict of interest.

\section{References}

1. Field, C.B., Behrenfeld, M.J., Randerson, J.T. \& Falkowski, P. Primary production of the biosphere: integrating terrestrial and oceanic components. Science 281, 237-240 (1998).

2. Kloareg, B. \& Quatrano, R. Structure of the cell walls of marine algae and ecophysiological functions of the matrix polysaccharides. Oceanogr. Mar. Biol. 26, 259-315 (1988).

3. Wargacki, A.J. et al. An engineered microbial platform for direct biofuel production from brown macroalgae. Science 335, 308-313 (2012).

4. Smetacek, V. \& Zingone, A. Green and golden seaweed tides on the rise. Nature 504, 84 (2013).

5. Liu, D. et al. The world's largest macroalgal bloom in the Yellow Sea, China: formation and implications. Estuar. Coast. Shelf Sci. 129, 2-10 (2013).

6. Ménesguen, A. \& Piriou, J.-Y. Nitrogen loadings and macroalgal (Ulva sp.) mass accumulation in Brittany (France). Ophelia 42, 227-237 (1995).

7. Lahaye, M. \& Robic, A. Structure and functional properties of ulvan, a polysaccharide from green seaweeds. Biomacromolecules 8, 1765-1774 (2007).

8. Lahaye, M., Brunel, M. \& Bonnin, E. Fine chemical structure analysis of oligosaccharides produced by an ulvan-lyase degradation of the water-soluble cellwall polysaccharides from Ulva sp. (Ulvales, Chlorophyta). Carbohydr. Res. 304, 325333 (1997).

9. Lahaye, M. NMR spectroscopic characterisation of oligosaccharides from two Ulva rigida ulvan samples (Ulvales, Chlorophyta) degraded by a lyase. Carbohydr. Res. 314, 1-12 (1998).

10. Ulaganathan, T. et al. New ulvan-degrading polysaccharide lyase family: structure and catalytic mechanism suggests convergent evolution of active site architecture. ACS Chem. Biol. 12, 1269-1280 (2017).

11. Ulaganathan, T., Banin, E., Helbert, W. \& Cygler, M. Structural and functional characterization of PL28 family ulvan lyase NLR48 from Nonlabens ulvanivorans. $J$. Biol. Chem. 293, 11564-11573 (2018). 
446

447

448

449

450

451

452

453

454

455

456

457

458

459

460

461

462

463

464

465

466

467

468

469

470

471

472

473

474

475

476

477

478

479

480

481

482

483

484

485

486

487

488

489

490

491

492

493

494

495

496

497

498

499

500

501

12. Ulaganathan, T., Helbert, W., Kopel, M., Banin, E. \& Cygler, M. Structure-function analyses of a PL24 family ulvan lyase reveal key features and suggest its catalytic mechanism. J. Biol. Chem. 293, 4026-4036 (2018).

13. Melcher, R.L., Neumann, M., Werner, J.P.F., Gröhn, F. \& Moerschbacher, B.M. Revised domain structure of ulvan lyase and characterization of the first ulvan binding domain. Sci. Rep. 7, 44115 (2017).

14. Reisky, $L$. et al. Biochemical characterization of an ulvan lyase from the marine flavobacterium Formosa agariphila KMM 3901 ${ }^{\top}$. Appl. Microbiol. Biotechnol. 102, 6987-6996 (2018).

15. Salinas, A. \& French, C.E. The enzymatic ulvan depolymerisation system from the alga-associated marine flavobacterium Formosa agariphila. Algal Res. 27, 335-344 (2017).

16. Collén, P.N. et al. A novel unsaturated $\beta$-glucuronyl hydrolase involved in ulvan degradation unveils the versatility of stereochemistry requirements in family $\mathrm{GH} 105$. J. Biol. Chem. 289, 6199-6211 (2014).

17. Foran, E. et al. Functional characterization of a novel "ulvan utilization loci" found in Alteromonas sp. LOR genome. Algal Res. 25, 39-46 (2017).

18. Mann, A.J. et al. The genome of the alga-associated marine flavobacterium Formosa agariphila $\mathrm{KMM} 3901^{\top}$ reveals a broad potential for degradation of algal polysaccharides. Appl. Environ. Microbiol. 79, 6813-6822 (2013).

19. Lombard, V., Golaconda Ramulu, H., Drula, E., Coutinho, P.M. \& Henrissat, B. The carbohydrate-active enzymes database (CAZy) in 2013. Nucleic Acids Res. 42, D490-D495 (2014).

20. Barbeyron, T. et al. Matching the diversity of sulfated biomolecules: creation of a classification database for sulfatases reflecting their substrate specificity. PLoS One 11, e0164846 (2016).

21. Mewis, K., Lenfant, N., Lombard, V. \& Henrissat, B. Dividing the large glycoside hydrolase family 43 into subfamilies: a motivation for detailed enzyme characterization. Appl. Environ. Microbiol. 82, 1686-1692 (2016).

22. Thomas, F. et al. Comparative characterization of two marine alginate lyases from Zobellia galactanivorans reveals distinct modes of action and exquisite adaptation to their natural substrate. J. Biol. Chem. 288, 23021-23037 (2013).

23. Demydchuk, M. et al. Insights into Hunter syndrome from the structure of iduronate-2sulfatase. Nat. Commun. 8, 15786 (2017).

24. Hanson, S.R., Best, M.D. \& Wong, C.H. Sulfatases: structure, mechanism, biological activity, inhibition, and synthetic utility. Angew. Chem. Int. Ed. 43, 5736-5763 (2004).

25. Hettle, A.G. et al. The molecular basis of polysaccharide sulfatase activity and a nomenclature for catalytic subsites in this class of enzyme. Structure 26, 747-758. e4 (2018).

26. Kopel, M. et al. New family of ulvan lyases identified in three isolates from the Alteromonadales order. J. Biol. Chem. 291, 5871-5878 (2016).

27. Sato, K. et al. A protein secretion system linked to bacteroidete gliding motility and pathogenesis. Proc. Natl. Acad. Sci. USA 107, 276-281 (2010).

28. Fujimoto, Z. et al. The structure of a Streptomyces avermitilis a-L-rhamnosidase reveals a novel carbohydrate-binding module CBM67 within the six-domain arrangement. J. Biol. Chem. 288, 12376-12385 (2013).

29. Caspi, R. et al. The MetaCyc database of metabolic pathways and enzymes. Nucleic Acids Res. 46, D633-D639 (2017).

30. Ryu, K.-S. et al. Structural insights into the monosaccharide specificity of Escherichia coli rhamnose mutarotase. J. Mol. Biol. 349, 153-162 (2005).

31. Richardson, J.S. et al. RhaU of Rhizobium leguminosarum is a rhamnose mutarotase. J. Bacteriol. 190, 2903-2910 (2008).

32. Korndörfer, I., Fessner, W.-D. \& Matthews, B.W. The structure of rhamnose isomerase from Escherichia coli and its relation with xylose isomerase illustrates a change between inter and intra-subunit complementation during evolution. J. Mol. Biol. 300, 917-933 (2000). 
502

503

504

505

506

507

508

509

510

511

512

513

514

515

516

517

518

519

520

521

522

523

524

525

526

527

528

529

530

531

532

533

534

535

536

537

538

539

540

541

542

543

544

545

546

33. Koch, H., Freese, H.M., Hahnke, R.L., Simon, M. \& Wietz, M. Adaptations of Alteromonas sp. 76-1 to Polysaccharide Degradation: A CAZyme Plasmid for Ulvan Degradation and Two Alginolytic Systems. Front Microbiol 10, 504 (2019).

34. Hehemann, J.H. et al. Aquatic adaptation of a laterally acquired pectin degradation pathway in marine gammaproteobacteria. Environ. Microbiol. 19, 2320-2333 (2017).

\section{Figure legends}

Fig. 1 | Genomic overview of putative ulvan PULs in marine Bacteroidetes and the proteomic response of the $F$. agariphila PUL to ulvan and rhamnose. a, Comparative genomics of ulvan PULs that contain the known PL28 ulvan lyase (connected with blue lines when over $50 \%$ identical) revealed that the enzymes are encoded by conserved genes in diverse marine Bacteroidetes genomes, including the model organism of this study, $F$. agariphila shown as \#1; the complete list of all analyzed strains is provided in panel 1c. SusD and TBDR proteins are colored as 'other' in this panel. b. Ulvan and rhamnose as sole carbon source elicit quantitative changes in proteins encoded in the putative ulvan PUL in $F$. agariphila. Bars indicate relative changes between both conditions. A positive $\Delta \log _{2}$ value corresponds to higher protein abundance with ulvan, while a negative value corresponds to higher protein abundance with rhamnose. Stars mark proteins that were exclusively quantified in either ulvan- or rhamnose-grown cells (see Supplementary Fig. 2, Table 1 and Supplementary Data Set 1). Arrows refer to the orientation of genes that encode the respective proteins. Proteins encoded by the ulvan PUL were numbered (P1-P39) and protein function was indicated (see Table 1). In the case of glycoside hydrolases $(\mathrm{GH})$ and sulfatases (S), families and subfamilies were specified ${ }^{19,20}$, e.g. GH2 (family) or S1_7 (family and subfamily). c, Co-occurrence analysis of genes in the predicted 12 putative bacteroidetal ulvan PULs highlights a conserved set of ulvan-degrading enzymes. The dendograms shown above and to the left of the similarity heat map depict the pairwise similarities between rows and columns, respectively.

Figure 2 | Structural analyses of ulvan specific sulfatases. a-c, Molecular surface of P18_S1_7 (a) and of the human iduronate 2-sulfatase (PDB: 5FQL) (b) both of which belong to the S1_7 subfamily, as well as of the S1_25 sulfatase module of P36 (P36_S1_25) (c). These molecular surfaces are colored according to electrostatic potential ranging from deep blue, +, to red, -. d-e, Fold representation of P18_S1_7 (d), of the human iduronate 2sulfatase (e) and of P36_S1_25 (f). The structures are shown in cartoon style. The a-helices and the $\beta$-strands are colored in cyan and magenta, respectively. $\mathbf{g}$. Stereo view of the key conserved residues in the catalytic groove of P18_S1_7. The amino acids are presented as sticks. The calcium ion is shown as a yellow sphere. The molecular surface of P18_S1_7 is shown as semi-transparent background. $\mathbf{h}$, Electron density around the catalytic calcium binding site of P18_S1_7. The coordination residues (Asp35, Asp36, Asp312 and His313) and the catalytic residue Cys74 are shown as sticks. Interactions with the calcium are represented by black dashed lines. The map shown is $\sigma A$-weighted $2 m F_{o}-D F_{c}$ maps contoured at $1.2 \sigma\left(0.07 \mathrm{e} / \AA^{3}\right)$.

Figure 3 | Zooming into the degradation of ulvan fragments. The experimental procedure to uncover the order of enzymes for ulvan degradation is shown exemplarily for an 
547

548

549

550

551

552

553

554

555

556

557

558

559

560

561

562

563

564

565

566

567

568

569

570

571

572

573

574

575

576

577

578

579

580

581

582

583

584

585

586

587

ulvan pentamer. All other investigated enzyme activities are shown in the Supplementary Information. All intermediate products were purified and their structures were confirmed by NMR and MS. MS spectra for individual oligomers are shown on the left next to the respective oligomer. Full spectra for all purified oligomers are shown in the Supplementary Information together with the corresponding NMR spectra. Red arrows indicate cleavage points of the following step. FACE gels for the analysis of the enzymatic interconversion steps are displayed on the right next to the respective enzyme. Full gel images including standards are shown in the Supplementary Information. The desulfation of Rha3S was detected by HPAEC-PAD and the full chromatograms are shown in the Supplementary Information. Numbers with " $S$ " attached to the sugar symbols indicate the position of sulfate groups.

Figure 4 | Structure of the L-rhamnose mutarotase P21_mutarotase. a, Stereo view of the P21_mutarotase dimer shown in cartoon style. $\mathbf{b}$, Stereo view of the molecular surface of the P21_mutarotase dimer color coded according to electrostatic potential ranging from deep blue, + , to red, -. c c. Electron density around the inter-subunit $\beta$-sheet in the mutarotase P21_mutarotase dimer. The $\beta 4$-strand found at the $C$-terminal extremity of the subunit $B$ is involved in $\beta$-sheet formation with the subunit $A$ through hydrogen bonding with the $\beta 2$ strand. Subunits $A$ and $B$ are green and yellow, respectively. Hydrogen bonds between $\beta 2$ and $\beta 4$ are shown as black dashed line. The map shown is $\sigma A$-weighted $2 m F_{o}-D F_{c}$ maps contoured at $1.2 \sigma\left(0.12 \mathrm{e} / \AA^{3}\right)$. d-e, Stereo view of the active site of P21_mutarotase (d) and of YiiL bound to an L-rhamnose (e). The amino acids are presented as sticks. The carbon atoms are colored in yellow and in cyan in P21_mutarotase and YiiL, respectively. The small red spheres are water molecules in the P21_mutarotase structure.

Figure 5 | Model of the ulvan degradation pathway in $F$. agariphila as suggested by the proteogenomic, biochemical and structural biological analyses in this study. Redundant pathways are omitted to maintain clarity. The ulvan molecule on top represents a part within the larger ulvan chain where rhamnose and iduronate are $\alpha$ - while xylose and glucuronate are $\beta$-configured. The formed products - at both ends of the initial ulvan molecule after cleavage with P30_PL28 - are not shown in the downstream degradation pathway. Activity of ulvan lyases P30_PL28 and P10_PLnc will form an unsaturated uronic acid residue from glucuronic acid or iduronic acid at the non-reducing end of the products. Numbers with "S" attached to the sugar symbols indicate the position of sulfate groups. Black arrows indicate pathways elucidated by proteogenomic, biochemical and structural biological analyses, while grey arrows only refer to proteome analyses or additional structural analyses in the case of P21_mutarotase. For numbering/nomenclature see Table 1. For reasons of simplicity, the linkage of the TBDRs to the TonB-ExbBD complex or a putative membrane association of certain enzymes were not included. KDG: 2-dehydro-3-deoxy-D-gluconate; DKI: 5-dehydro-4-deoxy-D-glucuronate; DKII: 3-deoxy-D-glycero-2,5-hexodiulosonate. 

not be quantified due to a lack of ${ }^{14} \mathrm{~N}$ signals (see Online Methods)

\begin{tabular}{|c|c|c|c|c|c|}
\hline \multicolumn{3}{|c|}{$\begin{array}{l}\text { PUL H-encoded proteins } \\
\text { (for ulvan and ulvan-derived monosaccharide utilization) }\end{array}$} & \multicolumn{3}{|c|}{$\log _{2}$ ratio } \\
\hline Abbreviation & Locus tag & Functional annotation & fru & rha & ulv \\
\hline P1_GH88 & *21900 & unsaturated glucuronyl hydrolase (GH88) & & & \\
\hline P2 SusD & *21910 & SusD-like protein & & & \\
\hline P3_TBDR & *21920 & TonB-dependent receptor & & & \\
\hline P4_HK & *21930 & histidine kinase & & & \\
\hline $\mathrm{P} 5$ isomerase & *21940 & 4-deoxy-L-threo-5-hexosulose-uronate ketol-isomerase & & & \\
\hline P6_dehydrogenase & *21950 & 2-deoxy-D-gluconate 3-dehydrogenase & & & \\
\hline P7 & *21960 & conserved hypothetical protein & & & \\
\hline P8 GH2 & *21970 & beta-galactosidase $(\mathrm{GH} 2)$ & & & \\
\hline P9_lactonase & *21980 & 6-phosphogluconolactonase & & & \\
\hline P10_PLnc & *21990 & ulvan lyase (PLnc) & & & \\
\hline P11_S1_7 & *22000 & iduronate-2-sulfatase (S1_7) & & & \\
\hline P12_S1_8 & *22010 & arylsulfatase (S1_8) & & & \\
\hline $\mathrm{P} 13 \mathrm{~S} 1 \mathrm{16}$ & *22020 & arylsulfatase (S1 16) & & & \\
\hline P14_S1_7 & *22030 & arylsulfatase (S1_7) & & & \\
\hline P15_GH2 & *22040 & glycoside hydrolase (GH2) & & & \\
\hline P16_GH2 & *22050 & beta-galactosidase $(\mathrm{GH} 2)$ & & & \\
\hline $\mathrm{P} 17{ }^{-} \mathrm{GH} 2$ & *22060 & beta-galactosidase $(\mathrm{GH} 2)$ & & & \\
\hline P18_S1_7 & *22070 & arylsulfatase (S1_7) & & & \\
\hline $\mathrm{P} 19 \mathrm{~S} 127$ & *22080 & sulfatase (S1 27) & & & \\
\hline P20_GH78 & *22090 & alpha-L-rhamnosidase $(\mathrm{GH} 78)$ & & & \\
\hline P21_mutarotase & *22100 & L-rhamnose mutarotase & & & \\
\hline $\mathrm{P} 22^{-}$ & *22110 & conserved hypothetical protein & & & \\
\hline P23 & *22120 & conserved hypothetical protein & & & \\
\hline P24_GH3 & *22130 & beta-glucosidase $(\mathrm{GH} 3)$ & & & \\
\hline P25 SusD & *22140 & SusD-like protein & & & \\
\hline P26_TBDR & *22150 & TonB-dependent receptor & & & \\
\hline P27_GH43 & *22160 & beta-xylosidase (GH43) & & & \\
\hline P28 GH78 & *22170 & alpha-L-rhamnosidase (GH78) & & & \\
\hline $\mathrm{P} 29^{-}$ & *22180 & conserved hypothetical protein & & & \\
\hline P30 PL28 & *22190 & ulvan lyase (PL28) & & & \\
\hline P31_GH39 & *22200 & glycoside hydrolase (GH39) & & & \\
\hline P32_S1_8 & *22210 & arylsulfatase (S1_8) & & & \\
\hline P33_GH105 & *22220 & glycoside hydrolase (GH105) & & & \\
\hline P34_GH3 & *22230 & beta-glucosidase (GH3) & & & \\
\hline P35_oxidoreductase & *22240 & oxidoreductase & & & \\
\hline P36_GH78/S1_25 & *22250 & alpha-L-rhamnosidase/sulfatase (GH78/S1_25) & & & \\
\hline P37 & *22260 & hypothetical protein & & & \\
\hline P38_SusD & *22270 & SusD-like protein & & & \\
\hline P39 TBDR & *22280 & TonB-dependent receptor & & & \\
\hline \multicolumn{3}{|c|}{$\begin{array}{l}\text { Non-PUL H-encoded proteins } \\
\text { (for ulvan-derived monosaccharide utilization) }\end{array}$} & \multicolumn{3}{|c|}{$\log _{2}$ ratio } \\
\hline Abbreviation & Locus tag & Functional annotation & fru & rha & ulv \\
\hline NP1_dehydrogenase & *21840 & aldehyde dehydrogenase $\mathrm{A}$ & & & \\
\hline NP2 dehydrogenase & *21850 & L-lactate dehydrogenase & & & \\
\hline NP3_aldolase & *21860 & class II aldolase/adducin family protein & & & \\
\hline NP4_kinase & *21870 & pentulose/hexulose kinase & & & \\
\hline NP5 isomerase & *21880 & rhamnose isomerase ${ }^{a}$ & & & \\
\hline NP6_aldolase & *21890 & rhamnulose-1-phosphate aldolase & & & \\
\hline NP7_kinase & *160 & xylulose kinase & & & \\
\hline NP8 isomerase & *170 & xylose isomerase & & & \\
\hline NP9_oxidoreductase & *9410 & D-mannonate oxidoreductase & & & \\
\hline NP10_dehydratase & *9420 & mannonate dehydratase & & & \\
\hline NP11 isomerase & *9430 & uronate isomerase & & & \\
\hline NP12_kinase & *9800 & 2-dehydro-3-deoxygluconate kinase & & & \\
\hline NP13_aldolase & *9820 & aldolase $\mathrm{b}^{\mathrm{b}}$ & & & \\
\hline NP14 kinase & *11640 & 2-dehydro-3-deoxygluconate kinase & & & \\
\hline NP15_kinase & *16400 & 2-dehydro-3-deoxygluconate kinase & & & \\
\hline NP16 XylE & *180 & $\mathrm{D}$-xylose transporter $\mathrm{XylE}^{\mathrm{C}}$ & & & \\
\hline NP17_ABC & *11090 & ABC transporter, ATP-binding protein & & & \\
\hline NP18_ABC & *25150 & ABC transporter, ATP-binding protein & & & \\
\hline NP19_ABC & *7480 & ABC transporter, ATP-binding protein & & & \\
\hline
\end{tabular}




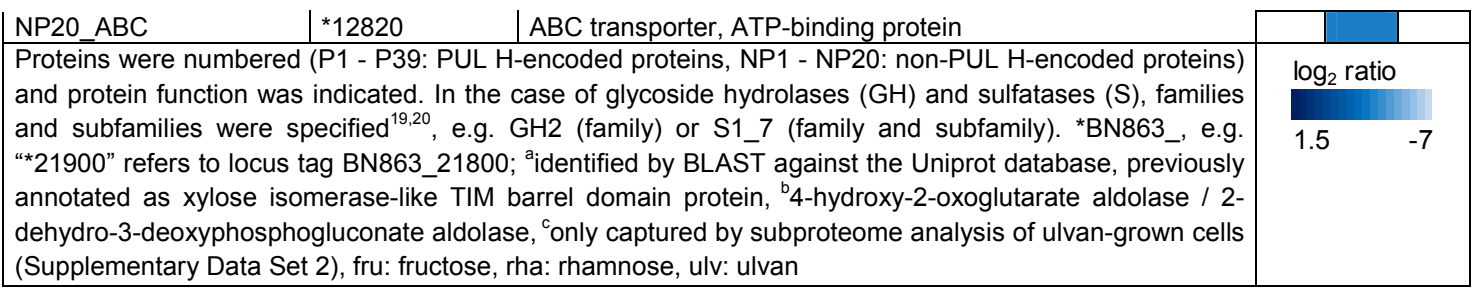

594

595

596 Online Methods

597

Prediction of ulvan PULs

598

599

600

601

602

603

604

605

606

607

608

609

610

611

612 the putative ulvan PUL boundary. Protein sequences within putative ulvan PULs were

613 collected for further analysis. Circos was used to visualize the different ulvan PULs ${ }^{39}$. Blastp

614 was used to calculate the identity between PL28 sequences from different ulvan PULs (cut-

615 off value: $1 \mathrm{e}-10$, over $50 \%$ identity). To simplify and reduce non-conserved proteins, domains

616

617

118,981 bacterial genomes were downloaded from the NCBI-GenBank using an in-house script (updated in 2018.09.10). Hmmer 3.0 was used to identify proteins with a PL28 or sulfatase domain, using a cut-off value of $1 \mathrm{e}-10^{35}$. Hidden Markov models of PL28 and sulfatase were obtained from dbCAN2 and the pfam database, respectively ${ }^{36,37}$. Models for the new PLnc family have not been released, thus blastp was used to identify its homologs, using $1 e-50$ and $30 \%$ sequence identity as cut-off values ${ }^{38}$. In each bacterial genome, if the adjacent 50 proteins to the afore-mentioned marker genes contained three marker genes (PL28, PLnc and sulfatase), this locus was considered as a potential ulvan PUL hit. To further determine PUL boundaries, 100 proteins surrounding the predicted ulvan PUL were collected and then locally annotated using pfam and dbCAN Hidden Marikov models (cut value 1e-10). Firstly, PL28 or PLnc families were set as boundaries, which were extended if adjacent genes are annotated as sugar utilization proteins, such as $\mathrm{GH}, \mathrm{PL}$, sugar transporter and transcription factors. In cases where five continuous genes were not related to sugar utilization or ulvan degradation, the last functionally relevant protein was taken as with less than $80 \%$ presence among the predicted ulvan PULs were excluded. Domain numbers in each PUL were counted, summarized and displayed in R studio. 
$A{ }^{14} \mathrm{~N} /{ }^{15} \mathrm{~N}$ relative quantification approach, based on metabolic labeling, was used for protein

621 quantification as described previously ${ }^{40}$. For this purpose, F. agariphila $\mathrm{KMM} 3901^{\top}$ was cultivated in MPM salts ${ }^{41}$ containing either ${ }^{14} \mathrm{~N}$ - or ${ }^{15} \mathrm{~N}$-ammonium chloride, supplemented with $0.2 \%$ of the individual carbon source: ulvan, rhamnose or fructose. Cultivation $\left(21^{\circ} \mathrm{C}\right.$,

$624170 \mathrm{rpm}$ ) comprised three steps: (i) $24 \mathrm{~h}$ of marine broth 2216-cultivation and subsequent (ii) 625 pre-cultures as well as (iii) main cultures in the above-described minimal medium. At an $626 \mathrm{OD}_{600 \mathrm{~nm}}$ of 0.5 , cells were harvested from main cultures by centrifugation ( $30 \mathrm{~min}, 9,384 \times g$, 627 $\left.4^{\circ} \mathrm{C}\right)$. Cell pellets were suspended in TE-buffer (10 mM Tris, $10 \mathrm{mM}$ EDTA) and cells were disrupted by sonication ( 4 cycles of $25 \mathrm{~s}$ at $5 \mathrm{~m} / \mathrm{s}$ ). Cell debris and protein extract were separated by centrifugation ( $10 \mathrm{~min}, 21,460 \times \mathrm{g}, 4{ }^{\circ} \mathrm{C}$ ). In case of the ${ }^{15} \mathrm{~N}$-labeled samples, 630 protein extracts of all samples from all 3 carbon sources were combined to form the ${ }^{15} \mathrm{~N}$ 631 labeled reference pool, which served as an internal standard. Protein concentration was determined using the Pierce ${ }^{\mathrm{TM}}$ BCA Protein Assay Kit (Thermo Fisher Scientific). $12.5 \mu \mathrm{g}$ of protein of each ${ }^{14} \mathrm{~N}$-sample was combined with $12.5 \mu \mathrm{g}$ protein of the ${ }^{15} \mathrm{~N}$-labeled pool. These 634 mixtures were separated by 1D-SDS-PAGE. Protein lanes were cut into ten equal-sized 635 pieces, destained and proteins were in-gel-digested with a $1 \mu \mathrm{g} \mathrm{mL}{ }^{-1}$ trypsin solution ${ }^{42}$. 636 Peptides were separated by RP chromatography and analyzed in an LTQ-Orbitrap Classic 637 mass spectrometer equipped with a nanoelectrospray ion source ${ }^{43}$. Data represent three 638 independent experiments $(n=3)$.

639 MS data were searched with Sorcerer SEQUEST v.27, rev.11 (Thermo-Finnigan, Thermo 640 Fisher Scientific, Germany) against a target decoy database including all F. agariphila KMM $6413901^{\top}$ protein sequences, corresponding reversed sequences (decoys) as well as common 642 laboratory contaminants (total 7224 entries)as described previously ${ }^{43}$, but using a false 643 positive rate of 0.05 . In brief, peak intensities of the ${ }^{14} \mathrm{~N}$-peptide ions of a protein versus its

$644{ }^{15} \mathrm{~N}$-peptide ions were compared to calculate a regression ratio. Only unique peptides and 
645 peptides with an $\mathrm{R}^{2}$ above 0.7 were taken into account. Non-quantified peptides were 646 manually checked. Average regression ratios were then exported. Proteins with at least two 647 quantified peptides were considered for the following calculations: ratios were median648 centered and log-transformed, termed as $\log _{2}$ ratios, per sample. If proteins were quantified 649 in at least two of the three replicates, means and standard deviations (SD) were calculated 650 from these values. In order to identify relative changes between the different carbon sources, $651 \log _{2}$ ratios of fructose- or rhamnose-cultivated cells were subtracted from $\log _{2}$ ratios of ulvan652 cultivated cells, termed $\Delta \log _{2}$. Fold-changes correspond to the exponentials of these $\Delta \log _{2}$ 653 values. Statistical analyses were performed with Welch's two-sided t-test (permutation-based 654 false discovery rate 0.01 ) using Perseus v1.6.0.7 44 , based on the $\log _{2}$ ratios. Putative 655 ON/OFF proteins were marked with $15 \mathrm{~N}$ (OFF) or $14 \mathrm{~N}(\mathrm{ON})$ in Supplementary Data Set 1 , 656 but were not included in any of the calculations. Only if a protein was identified as an 657 ON/OFF protein in all three replicates, it was assigned to a fixed value (10/-10), to highlight 658 these proteins.

\section{Subproteome fractionation}

660 F. agariphila $\mathrm{KMM} 3901^{\top}$ was cultivated as described above, except that no ${ }^{15} \mathrm{~N}$-labeling was 661 performed and only ulvan was applied as a carbon source.

662 For the surface proteome (trypsin-shaving approach), $1.5 \mathrm{~mL}$ of cell suspension was 663 removed from the culture and centrifuged $\left(5 \mathrm{~min}, 5,867 \times g, 4{ }^{\circ} \mathrm{C}\right)$. Cells were washed with $66450 \mathrm{mM}$ triethylammoniumbicarbonate-buffer (TEAB) and finally resuspended in $45 \mu \mathrm{L}$ TEAB665 buffer. In order to cleave proteins from the cell surface, $5 \mu \mathrm{L}$ of a $1 \mu \mathrm{g} \mathrm{mL}^{-1}$ trypsin solution 666 was added. The solution was transferred onto a $0.22 \mu \mathrm{m}$ cellulose-acetate spin-column and 667 incubated for $15 \mathrm{~min}$ at $900 \mathrm{rpm}$ and $37^{\circ} \mathrm{C}$. The flow-through was collected by centrifugation 668 (10 $\left.\min , 4,000 \times g, 4{ }^{\circ} \mathrm{C}\right)$, another $1 \mu \mathrm{L}$ of trypsin was added and the sample was incubated 669 at $900 \mathrm{rpm}$ and $37^{\circ} \mathrm{C}$ overnight. The peptide mixture was desalted using $\mathrm{C} 18$ StageTips.

670 The following solutions were used: $0.1 \%(\mathrm{v} / \mathrm{v})$ acetic acid in ultra-pure water (buffer $\mathrm{A})$ and $6710.1 \%(\mathrm{v} / \mathrm{v})$ acetic acid in acetonitrile (buffer B). Before the sample was added, C18 material 
672 was rinsed and equilibrated with buffer $A$ and washed with buffer B in between these steps.

673 After the sample was added, buffer A was used for washing and buffer B for elution.

674 In the case of cytosolic, membrane-associated and extracellular protein fractions, $100 \mathrm{~mL}$ of 675 cell suspension was harvested by centrifugation (30 min, 9,384 x g, $4{ }^{\circ} \mathrm{C}$ ). Cell pellets and 676 supernatants were processed separately as previously described ${ }^{45,46}$. 1D-SDS-PAGE, in-gel677 digestion and LC-MS/MS analysis were performed as described above. Experiments were 678 carried out in triplicates $(n=3)$.

679 Database searches were done with Sorcerer SEQUEST v.27, rev.11 (see above). Results 680 were summarized and filtered using Scaffold 4.4.1.1 (Proteome Software, Portland, OR, 681 USA): protein and peptide false discovery rate was set to 0.01 and protein identification 682 required two peptides minimum. For protein quantification, the normalized spectral 683 abundance factor was calculated for each protein giving the percentage (\%NSAF) of all 684 proteins in the same sample ${ }^{47}$. If proteins were identified in at least two of the three 685 replicates, they were considered for further calculations.

\section{Gene cloning and expression}

687 Expression constructs were prepared using the FastCloning strategy ${ }^{48}$ with genomic DNA 688 from F. agariphila KMM $3901^{\top}$ (collection number DSM15362 at DSMZ, Braunschweig, 689 Germany) as template for the amplification of the inserts. Generally, the pET28 constructs were prepared as described previously ${ }^{14}$ with the gene primers shown in Supplementary

691 Table 10. To clone the gene for the formylglycine-generating enzyme (FGE) from $F$. 692 agariphila, the vector backbone was amplified with the primers 5'-AATA GCGC CGTC GACC 693 ATCA TCAT CATC ATCAT-3' and 5'-CATG GTTA ATTC CTCC TGTT AGCC CAAA AA-3' 694 from $\mathrm{pBAD} / \mathrm{myc}-\mathrm{his} \mathrm{A}$. For the pFA, constructs were cloned and overexpressed as previously 695 described ${ }^{49}$. Briefly, genes were PCR-amplified using the NEB Q5 High-Fidelity DNA 696 Polymerase system. PCR reactions were done with 30 cycles (denaturation: $95{ }^{\circ} \mathrm{C}$; 697 annealing: $60{ }^{\circ} \mathrm{C}$; elongation: $72^{\circ} \mathrm{C}$ ) using 0.5 units of enzyme in a total reaction of $50 \mu \mathrm{L}$ 
698

699

700

701

702

703

704

705

706

707

708

709

710

711

712

713

714

715

716

717

718

719

720

721

722

723

724

using the primers shown in Supplementary Table 10. Amplicons were cleaned up using the QIAquick PCR Purification Kit (Qiagen) and digested with the appropriate restriction endonucleases. All ligations were done in the linearized T7 system vector pFO4.

Genes encoding the sulfatases P18_S1_7, P19_S1_27, P32_S1_8 and P36_S1_25 were ordered codon-optimized for E. coli and sub-cloned into pET28 with Nhel and Xhol from Genscript. The optimized nucleotide sequences are shown in the Supplementary Information.

Escherichia coli BL21(DE3) was transformed with pET28-based plasmids. For the overexpression, $50 \mathrm{~mL}$ ZYP-5052 ${ }^{50}$ with $100 \mu \mathrm{g} \mathrm{mL} \mathrm{m}^{-1}$ kanamycin were inoculated from an overnight culture in LB containing $50 \mu \mathrm{g} \mathrm{mL}^{-1}$ kanamycin. The culture was grown at $30{ }^{\circ} \mathrm{C}$ and $180 \mathrm{rpm}$ until the $\mathrm{OD}_{600 \mathrm{~nm}}$ reached 1.0 and was then cooled to $20{ }^{\circ} \mathrm{C}$ for $48 \mathrm{~h}$. In the case of sulfatases, the formylglycine-generating enzyme (FGE) from F. agariphila was coexpressed. LB medium with $100 \mu \mathrm{g} \mathrm{mL}^{-1}$ ampicillin and $50 \mu \mathrm{g} \mathrm{mL}^{-1}$ kanamycin was inoculated from an overnight culture in the same medium and incubated at $37^{\circ} \mathrm{C}$ and $180 \mathrm{rpm}$ until the $\mathrm{OD}_{600 \mathrm{~nm}}$ reached 0.3 to 0.5 . After the addition of $1.5 \mathrm{mM}$ L-arabinose and incubation for 90 $\min$ at $37{ }^{\circ} \mathrm{C}$, the culture was cooled to $18{ }^{\circ} \mathrm{C}$ for $2 \mathrm{~h}$ before $0.5 \mathrm{mM}$ isopropyl $\beta$-D-1thiogalactopyranoside (IPTG) was added and the culture was incubated overnight at $18{ }^{\circ} \mathrm{C}$. Alternatively, sulfatases were expressed from the pFA constructs in E. coli BL21(DE3) cells grown in LB medium supplemented with $15 \mu \mathrm{g} \mathrm{m} \mathrm{L}^{-1}$ ampicillin, at $37^{\circ} \mathrm{C}$, until reaching an $\mathrm{OD}_{600 \mathrm{~nm}}$ of 0.8 . Expression was induced with $0.1 \mathrm{mM}$ IPTG overnight at $18{ }^{\circ} \mathrm{C}$. For crystallization screening, E. coli BL21(DE3) cells were transformed with the plasmids containing the gene fragment of interest, then grown in the autoinduction Zyp-5052 medium (200 $\mathrm{Mg} \mathrm{mL}^{-1}$ ampicillin, $\left.20^{\circ} \mathrm{C}, 72 \mathrm{~h}\right)$. Cells were harvested by centrifugation $(10,000 \times \mathrm{g}, 4$ ${ }^{\circ} \mathrm{C}, 20 \mathrm{~min}$ ) and the cell pellets were stored at $-20{ }^{\circ} \mathrm{C}$ until further use.

Samples from the cultivations equivalent to $1 \mathrm{~mL}$ of culture with an $\mathrm{OD}_{600 \mathrm{~nm}}$ of 7 were taken before harvest and the cells were collected by centrifugation $\left(13,000 \times g, 4{ }^{\circ} \mathrm{C}, 2 \mathrm{~min}\right)$. Pellets were resuspended in $500 \mu \mathrm{L} 50 \mathrm{mM}$ HEPES with $100 \mathrm{mM} \mathrm{NaCl}$ (pH 7.4). After 
chemical lysis with BugBuster (Merck, Darmstadt, Germany), whole cell protein (W) samples were obtained prior to removal of the cell debris by centrifugation $\left(13,000 \times g, 4{ }^{\circ} \mathrm{C}, 10 \mathrm{~min}\right)$. Samples of the soluble protein fraction (S) were taken from the respective supernatant.

\section{Enzyme purification}

Cell pellets were thawed and resuspended in $50 \mathrm{mM} \mathrm{NaPi}$ with $300 \mathrm{mM} \mathrm{NaCl}(\mathrm{pH} 8.0)$ and lysed by three cycles of sonication ( $2.0 \mathrm{~min}, 30 \%$ pulse, $50 \%$ power). After centrifugation $\left(10,000 \times g, 4{ }^{\circ} \mathrm{C}, 20 \mathrm{~min}\right)$, the supernatant was filtered $(0.45 \mu \mathrm{m})$ and loaded onto a $5 \mathrm{~mL}$ HisTrap FF crude column (GE Healthcare, Freiburg, Germany) equilibrated with lysis buffer. Alternatively, Rotigarose-His/Ni beads (Karl Roth, Karlsruhe, Germany) were used in gravity flow columns. After washing, the protein was eluted with $50 \mathrm{mM} \mathrm{NaPi}$ and $300 \mathrm{mM} \mathrm{NaCl}$ containing $300 \mathrm{mM}$ imidazole $(\mathrm{pH}$ 8.0). Fractions containing the protein of interest were pooled and desalted using PD-10 columns (GE Healthcare, Freiburg, Germany) equilibrated with $50 \mathrm{mM} \mathrm{NaPi} \mathrm{pH} \mathrm{7.4.} \mathrm{Proteins} \mathrm{were} \mathrm{analyzed} \mathrm{by} \mathrm{SDS-PAGE} \mathrm{on} 12.5 \%$ acrylamide gels. $1 \%(\mathrm{v} / \mathrm{v})$ 2,2,2-trichloroethanol was used for the visualization of proteins under UV light ${ }^{51}$. Alternatively, proteins were stained with Coomassie Blue (PhastGel ${ }^{\circledR}$ Blue R). All enzymes were used undiluted, or in dilutions of $1: 5,1: 10$ or 1:20 with enzyme storage buffer (Supplementary Table 11).

Alternatively, cells were subjected to mechanical lysis and cytoplasmic extracts were loaded onto an Histrap column ( $5 \mathrm{ml}$, GE Healthcare) equilibrated with $50 \mathrm{mM}$ Tris, $0.2 \mathrm{M} \mathrm{NaCl}, 20$ $\mathrm{mM}$ imidazol, $1 \mathrm{mM} \mathrm{CaCl}_{2}$ at $\mathrm{pH}$ 8.0. Recombinant proteins were eluted with around $250 \mathrm{mM}$ imidazole and then loaded onto a Hiprep Desalting column (26/10,53ml, GE Healthcare) in order to eliminate the imidazole, which notably interfered with sulfatase activity. Purified enzymes were concentrated $\left(\right.$ Amicon ${ }^{\circledR}$ Ultra Centrifugal Filter, $30 \mathrm{kDa}$ ) to a concentration of $1 \mathrm{mg} \mathrm{mL}^{-1}$ (Nanodrop). 


\section{Purification of ulvan}

751 Green tide Ulva sp. was collected near Roscoff (France) and dried. Alternatively, dried Ulva

752 biomass from the Atlantic coast in Spain was purchased as organic sea lettuce (Kulau, 753 Berlin, Germany). Ulvan was extracted according to the literature ${ }^{52}$. The dialysis step was 754 exchanged by precipitation with acetone $(80 \%(\mathrm{v} / \mathrm{v})$ final concentration). After washing, 755 acetone-precipitated ulvan was dissolved in deionized water and freeze-dried. Alternatively, 756 ulvan was obtained from Agrival (Plouenan, France) or Elicityl (Grenoble, France).

\section{$757 \quad$ Enzyme assays}

758 Generally, reactions were performed in 50 mM HEPES pH 7.4 with $100 \mathrm{mM} \mathrm{NaCl}$ or $35 \mathrm{mM}$ 759 Tris $\mathrm{pH} 8.0$ with $50 \mathrm{mM} \mathrm{NaCl}$. Initial degradation of ulvan into larger oligomers was monitored 760 by C-PAGE, while smaller degradation products and the conversion of purified oligomers 761 was analyzed by FACE. For lyases, the increase in absorbance at $235 \mathrm{~nm}$ was recorded 762 over time. For unsaturated uronyl hydrolases (GH88 and $\mathrm{GH} 105$ ), the decrease in 763 absorbance at $235 \mathrm{~nm}$ of ulvan lyase products was monitored. For screening reactions, $10 \%$ $764(\mathrm{v} / \mathrm{v})$ clarified lysate as used for the SDS-PAGE was added. Untreated ulvan was generally 765 used at a concentration of $1 \mathrm{~g} \mathrm{~L}^{-1}$ while purified oligomers were used at $0.25 \mathrm{mg} \mathrm{mL}^{-1}$. 766 Incubation was performed overnight at room temperature.

\section{Sulfatase activity assay on ulvan polymers}

768 Activity assays were conducted on three different ulvan polymers from Ulva species: a 769 commercial ulvan from Elicityl (Grenoble, France), an ulvan which was a gift from the 770 company Agrival (Plouenan, France), and an ulvan extracted from Ulva sp. harvested on 771 Brittany north coast (Roscoff, France). $10 \mu \mathrm{L}$ of each ulvan solution $\left(1 \% \mathrm{w} / \mathrm{v}\right.$ in $\left.\mathrm{H}_{2} \mathrm{O}\right)$ was

772 incubated with $10 \mu \mathrm{L}$ of purified sulfatase $\left(1 \mathrm{mg} \mathrm{mL}^{-1}\right)$ in a final volume of $80 \mu \mathrm{L}$ of $25 \mathrm{mM}$

773 Tris- $\mathrm{HCl}, 0.1 \mathrm{M} \mathrm{NaCl}, 0.5 \mathrm{mM} \mathrm{CaCl}_{2}, \mathrm{pH} 8.0$ buffer mix, for $18 \mathrm{~h}$ at $37^{\circ} \mathrm{C}$. For each reaction, 774 a control sample was prepared using similar conditions but with an inactivated enzyme 
$775\left(100{ }^{\circ} \mathrm{C}, 10 \mathrm{~min}\right)$. Reaction mixtures and blanks were then filtered (10 kDa, Amicon ${ }^{\circledR}$ Ultra, 776 Millipore) to measure the amount of free sulfate in the filtrates.

777 Ulvan-specific sulfatase activity was measured by high-performance anion-exchange 778 chromatography (HPAEC). Using an ICS5000 system (Thermo Scientific Dionex), anions 779 from reaction mixture filtrates were injected (AS-AP Autosampler) and separated using an 780 AG11-HC guard column $(4 \times 50 \mathrm{~mm})$ mounted in series with an AS11-HC anion-exchange 781 column $(4 \times 250 \mathrm{~mm})$. Elutions were performed with isocratic $12 \mathrm{mM} \mathrm{NaOH}$ at a flow rate of 1 $782 \mathrm{~mL} \mathrm{~min}^{-1}$ (Single Pump-5), and the detection of anions was leaded by an Analytical CD 783 Conductivity Detector associated to a suppressor (ASRS 500, $4 \mathrm{~mm}$ ) running at $50 \mathrm{~mA}$. 784 Using a standard curve of sulfate, concentration of sulfate released by the enzymatic 785 reaction was calculated from the difference of the amount of sulfate between samples and 786 the associated blanks.

\section{Sulfatase activity assay on characterized ulvan oligosaccharides}

$78810 \mu \mathrm{L}$ of ulvan oligosaccharides $\left(0.5-1 \% \mathrm{w} / \mathrm{v}\right.$ in $\left.\mathrm{H}_{2} \mathrm{O}\right)$ were incubated with $15 \mu \mathrm{L}$ of purified 789 sulfatase $\left(0.5 \mathrm{mg} \mathrm{mL}^{-1}\right)$ in a final volume of $75 \mu \mathrm{L}$ of $5 \mathrm{mM}$ Tris- $\mathrm{HCl}, 10 \mathrm{mM} \mathrm{NaCl}, 0.5 \mathrm{mM}$ $790 \mathrm{CaCl}_{2}, \mathrm{pH} 8.0$ buffer, for $18 \mathrm{~h}$ at $37{ }^{\circ} \mathrm{C}$. The recombinant enzymes P33_GH105 or 791 P36_GH78 were added $\left(2 \mu \mathrm{L}-3 \mathrm{mg} \mathrm{mL}^{-1}\right)$. Each reaction mixture was centrifuged $(14,000 \mathrm{x}$ $792 g$ for $10 \mathrm{~min}$ ) before injection. Oligosaccharide detection was realized by HPAEC analyzes 793 on the same ICS 5000 system described for the sulfate quantification. Elutions were 794 performed at a flow rate of $0.5 \mathrm{~mL} \mathrm{~min}^{-1}$ using a $\mathrm{NaOH}$ multistep gradient from 8 to $280 \mathrm{mM}$ 795 (45 $\mathrm{min}$ ). Oligosaccharides were detected by conductivity mode under a current suppression 796 of $50-300 \mathrm{~mA}$.

\section{Carbohydrate polyacrylamide gel electrophoresis}

798 Fluorophore-assisted carbohydrate electrophoresis (FACE) was performed with 2799 aminoacridone (AMAC) as fluorophore ${ }^{53}$. 
800 For carbohydrate polyacrylamide gel electrophoresis (C-PAGE), samples were mixed with an 801 equal volume of FACE loading buffer ${ }^{53}$. Gels and running conditions were identical to FACE. 802 Carbohydrates were visualized by staining with Stains-All solution $\left(0.25 \mathrm{~g} \mathrm{~L}^{-1}\right.$ in $1.7 \mathrm{mM}$ Tris$803 \mathrm{HCl} \mathrm{pH} 7.5$ with $25 \%(\mathrm{v} / \mathrm{v})$ isopropanol). The gels were destained with $25 \%(\mathrm{v} / \mathrm{v})$ isopropanol 804 in deionized water.

805

806

807

808

809

810

811

812

813

814

815

816

817

818

819

820

821

822

823

824

825

\section{Purification of oligomers and structure determination}

Ulvan was digested with purified enzymes in Tris- $\mathrm{HCl} \mathrm{pH} 8.5$ at room temperature. Oligomers were separated on two XK 26/100 (GE Healthcare, Freiburg, Germany) in series filled with Bio-Gel P-2 (Rio-Rad, Munich, Germany) using $100 \mathrm{mM}\left(\mathrm{NH}_{4}\right)_{2} \mathrm{CO}_{3}$ as mobile phase at a flow rate of $1 \mathrm{~mL} \mathrm{~min}{ }^{-1}$. After lyophilization of the fractions containing the products, oligomers were dissolved in $\mathrm{D}_{2} \mathrm{O}$ and lyophilized three times before NMR spectra were recorded on a Bruker Avance III HD 600 (600 MHz) spectrometer (Bruker, Billerica, USA) in $D_{2} \mathrm{O}$ solutions. The structures were independently elucidated based on $1 \mathrm{D}$ and $2 \mathrm{D}$ (COSY, HSQC, HMBC, TOCSY) methods and the assigned ${ }^{1} \mathrm{H}$ and ${ }^{13} \mathrm{C}-\mathrm{NMR}$ signals were then compared with literature data, showing excellent consistency $^{8,9}$. For samples containing uronic acid structures, it was required to neutralize the otherwise acidic NMR samples with $\mathrm{Na}_{2} \mathrm{HPO}_{4}$ to $\mathrm{pH}$ 7-8 ( $\mathrm{pH}$-electrode calibrated to $\mathrm{H}^{+}$) in order to achieve fully resolved signals for the carboxylic acid and neighboring positions $\left({ }^{13} \mathrm{C}\right)$. HPLC-ELS-MS analysis was performed by injection of $\sim 0.1 \%$ solutions $(1-5 \mu \mathrm{L})$ on a Nexera UHPLC system from Shimadzu (equipped with two binary LC-30AD pumps plus degassers, a CTO-20 column oven) and a LCMS-2200 EV MS-detector and an additional ELS-detector (JASCO ELS2041). Analysis was performed with mobile phase $A=\mathrm{H}_{2} \mathrm{O}(0.1 \% \mathrm{HCOOH})$ and mobile phase $\mathrm{B}=\mathrm{CH}_{3} \mathrm{CN}$ on a $\mathrm{C} 18$ column (XSelect CSH XP C18 $2.5 \mu \mathrm{m} 3 \times 50 \mathrm{~mm}$ ) at $40{ }^{\circ} \mathrm{C}$. Flow rate was $1.3 \mathrm{~mL} \mathrm{~min}^{-1}(0-3 \mathrm{~min})$ with $5 \% \mathrm{~B}$ from $0-0.15 \mathrm{~min}, 5-98 \% \mathrm{~B}$ from $0.15-2.2$ min and $98 \%-5 \%$ B from $2.2-2.5$ min.

\section{Crystallization of proteins and structure determination}


826 Crystallization trials of P18_S1_7 (pFA13 construct) and of the family S1_25 sulfatase 827 module of the bimodular GH78 L-rhamnosidase P36 (pET28 construct, referred to as 828 P36_S1_25) were undertaken at room temperature using the vapor-diffusion method in 829 sitting drops containing a 2:1 ratio of pure protein (12.9 and $13.0 \mathrm{mg} \mathrm{mL}^{-1}$, respectively) and 830 of precipitant solution. P18_S1_7 and P36_S1_25 were mixed with reservoir solution 831 containing $100 \mathrm{mM}$ MIB pH 5.0 and $25 \%$ PEG 1,500 and $100 \mathrm{mM} \mathrm{MES} \mathrm{pH} 6.5$ and $25 \%$ 832 PEG 2,000 MME, respectively. Crystals of the L-rhamnose mutarotase P21_mutarotase 833 (pFA16 construct, concentration: $14.9 \mathrm{mg} \mathrm{mL}^{-1}$ ) were obtained by the hanging-drop vapor834 diffusion method at room temperature and also at a 2:1 protein/precipitant ratio with a 835 reservoir solution containing $100 \mathrm{mM}$ sodium acetate $\mathrm{pH} 4.6$ and $4.3 \mathrm{M}$ sodium formate. 836 Crystals of P18_S1_7, P21_mutarotase and P36_S1_25 were cryoprotected with 10\%, 14\% 837 and $14 \%$ glycerol, respectively, and flash-frozen in liquid nitrogen. X-ray diffraction 838 experiments were carried out at $100 \mathrm{~K}$ at beamlines PROXIMA-1 (PX1) for P18_S1_7 and 839 P21_mutarotase and PROXIMA-2 for P36_S1_25 (SOLEIL Synchrotron, GIF-sur-YVETTE, 840 France). Diffraction data of P18_S1_7, P21_mutarotase and P36_S1_25 were obtained at $8411.23,1.47$ and $2.91 \AA$, respectively, and were processed using $\mathrm{XDS}^{54}$. Scaling and merging 842 were performed using the program Aimless from the CCP4 package ${ }^{55}$. The structure of 843 P21_mutarotase (a dimer of 2 x 115 residues), P18_S1_7 (475 residues), and P36_S1_25 844 (467 residues) were solved by molecular replacement with the CCP4 suite program MolRep ${ }^{56}$ 845 using the structures of the rhamnose mutarotase RhaU from Rhizobium leguminosarum 846 (PDB entry: 2QLX) ${ }^{31}$, of the human iduronate-2-sulfatase (5FQL) ${ }^{23}$ and of the putative 847 sulfatase YidJ from Bacteroides fragilis (2QZU) as starting models, respectively. Refinement 848 and model building of P18_S1_7 and P21_mutarotase were undertaken using the PHENIX 849 program suite ${ }^{57}$ and the Coot software ${ }^{58}$. Initial refinement of the P36_S1_25 structure was 850 performed with BUSTER ${ }^{59}$ and $\mathrm{PHENIX}^{57}$, and then manual examination and rebuilding of 851 the refined coordinates were carried out in $\operatorname{Coot}^{58}$. Structural validation was undertaken using 852 MOLPROBITY60. 
854 mother liquor in the JBScreen PACT ++ HTS and JBScreen Classic HTS I (Jena 855 Bioscience). A single crystal from the screen grown in $20 \%$ PEG 3350, $0.1 \mathrm{M}$ Bis-Tris pH $8567.5,0.2 \mathrm{M}$ sodium bromide was cryo-protected in $30 \%$ glycerol prior X-ray crystallography. 857 The diffraction data were collected at DESY P11 automatically integrated in XDS and scaled 858 and merged in Aimless ${ }^{54,61}$.

859 The structure of P17_GH2 was solved by molecular replacement using 5dmy as search 860 model in phaser ${ }^{62}$. The structure was built automatically using buccaneer and manually in 861 Coot building directly into the $2 \mathrm{Fo}-\mathrm{Fc}$ maps $^{58,63}$. Structural validation was carried out using MOLPROBITY ${ }^{60}$.

863

864

865

866

867

868

869

870

871

872

873

874

875

876

877

878

879

880

881

882

883

884

885

886

\section{Data availability}

All data that support the findings of this study are available from the corresponding authors upon reasonable request. The protein structures are deposited in the PDB under 6HHM, 6HHN, 6HPD and 6HR5. Mass spectrometry data were deposited to the ProteomeXchange Consortium via the PRIDE partner repository ${ }^{64}$ with the dataset identifier PXD009299. The sequences of the newly characterized ulvan-degrading enzymes can be found in the GenBank sequence database under the respective locus tags mentioned in Table 1.

\section{References}

35. Finn, R.D., Clements, J. \& Eddy, S.R. HMMER web server: interactive sequence similarity searching. Nucleic Acids Res. 39, W29-W37 (2011).

36. Zhang, $\mathrm{H}$. et al. dbCAN2: a meta server for automated carbohydrate-active enzyme annotation. Nucleic Acids Res. 46, W95-W101 (2018).

37. Finn, R.D. et al. Pfam: the protein families database. Nucleic Acids Res. 42, D222D230 (2013).

38. Camacho, C. et al. BLAST+: architecture and applications. BMC Bioinformatics 10, 421 (2009).

39. Krzywinski, M.I. et al. Circos: an information aesthetic for comparative genomics. Genome Res. 9, 1639-1645 (2009).

40. MacCoss, M.J., Wu, C.C., Liu, H., Sadygov, R. \& Yates, J.R., 3rd. A correlation algorithm for the automated quantitative analysis of shotgun proteomics data. Anal. Chem. 75, 6912-6921 (2003).

41. Schut, F. et al. Isolation of typical marine bacteria by dilution culture: growth, maintenance, and characteristics of isolates under laboratory conditions. Appl. Environ. Microbiol. 59, 2150-2160 (1993). 
887

888

889

890

891

892

893

894

895

896

897

898

899

900

901

902

903

904

905

906

907

908

909

910

911

912

913

914

915

916

917

918

919

920

921

922

923

924

925

926

927

928

929

930

931

932

933

934

935

936

42. Grube, M. et al. Exploring functional contexts of symbiotic sustain within lichenassociated bacteria by comparative omics. ISME J. 9, 412-424 (2015).

43. Otto, A. et al. Systems-wide temporal proteomic profiling in glucose-starved Bacillus subtilis. Nat. Commun. 1, 137 (2010).

44. Tyanova, S. \& Cox, J. Perseus: a bioinformatics platform for integrative analysis of proteomics data in cancer research. Methods Mol. Biol. 1711, 133-148 (2018).

45. Antelmann, $\mathrm{H}$. et al. A proteomic view on genome-based signal peptide predictions. Genome Res. 11, 1484-1502 (2001).

46. Eymann, C. et al. A comprehensive proteome map of growing Bacillus subtilis cells. Proteomics 4, 2849-2876 (2004).

47. Zybailov, B. et al. Statistical analysis of membrane proteome expression changes in Saccharomyces cerevisiae. J. Proteome Res. 5, 2339-2347 (2006).

48. Li, C. et al. FastCloning: a highly simplified, purification-free, sequence-and ligationindependent PCR cloning method. BMC Biotechnol. 11, 92 (2011).

49. Groisillier, A. et al. MARINE-EXPRESS: taking advantage of high throughput cloning and expression strategies for the post-genomic analysis of marine organisms. Microb. Cell Fact. 9, 45 (2010).

50. Studier, F.W. Protein production by auto-induction in high-density shaking cultures. Protein Expr. Purif. 41, 207-234 (2005).

51. Ladner, C.L., Yang, J., Turner, R.J. \& Edwards, R.A. Visible fluorescent detection of proteins in polyacrylamide gels without staining. Anal. Biochem. 326, 13-20 (2004).

52. Robic, A., Gaillard, C., Sassi, J.F., Lerat, Y. \& Lahaye, M. Ultrastructure of ulvan: a polysaccharide from green seaweeds. Biopolymers 91, 652-664 (2009).

53. Hehemann, J.H. et al. Transfer of carbohydrate-active enzymes from marine bacteria to Japanese gut microbiota. Nature 464, 908-912 (2010).

54. Kabsch, W. Integration, scaling, space-group assignment and post-refinement. Acta Crystallogr. D Biol. Crystallogr. 66, 133-144 (2010).

55. Winn, M.D. et al. Overview of the CCP4 suite and current developments. Acta Crystallogr. D Biol. Crystallogr. 67, 235-242 (2011).

56. Vagin, A. \& Teplyakov, A. Molecular replacement with MOLREP. Acta Crystallogr. D Biol. Crystallogr. 66, 22-25 (2010).

57. Adams, P.D. et al. PHENIX: a comprehensive Python-based system for macromolecular structure solution. Acta Crystallogr. D Biol. Crystallogr. 66, 213-221 (2010).

58. Emsley, P., Lohkamp, B., Scott, W.G. \& Cowtan, K. Features and development of Coot. Acta Crystallogr. D Biol. Crystallogr. 66, 486-501 (2010).

59. Smart, O.S. et al. Exploiting structure similarity in refinement: automated NCS and target-structure restraints in BUSTER. Acta Crystallogr. D Biol. Crystallogr. 68, 368380 (2012).

60. Chen, V.B. et al. MolProbity: all-atom structure validation for macromolecular crystallography. Acta Crystallogr. D Biol. Crystallogr. 66, 12-21 (2010).

61. Evans, P.R. \& Murshudov, G.N. How good are my data and what is the resolution? Acta Crystallogr. D Biol. Crystallogr. 69, 1204-1214 (2013).

62. McCoy, A.J. et al. Phaser crystallographic software. J. Appl. Crystallogr. 40, 658-674 (2007).

63. Cowtan, K. The Buccaneer software for automated model building. 1. Tracing protein chains. Acta Crystallogr. D Biol. Crystallogr. 62, 1002-1011 (2006).

64. Vizcaíno, J.A. et al. 2016 update of the PRIDE database and its related tools. Nucleic Acids Res. 44, D447-D456 (2016). 
Table 1 | List of PUL H-encoded and relevant non-PUL H-encoded proteins with abbreviations used in the text, corresponding locus tags and functional annotation as well as their relative abundance (mean $\log _{2}$ ratio) with the respective carbon source. Empty/white squares refer to non-quantified proteins while grey squares indicate OFF-proteins that could not be quantified due to a lack of ${ }^{14} \mathrm{~N}$ signals (see Online Methods) 


\begin{tabular}{|c|c|c|c|c|c|}
\hline $\begin{array}{l}\text { PUL H-encoded pro } \\
\text { (for ulvan and ulvan }\end{array}$ & ived monos & laride utilization) & & $g_{2}$ rati & \\
\hline Abbreviation & Locus tag & Functional annotation & fru & rha & ulv \\
\hline P1_GH88 & *21900 & unsaturated glucuronyl hydrolase (GH88) & & & \\
\hline P2_SusD & *21910 & SusD-like protein & & & \\
\hline P3_TBDR & *21920 & TonB-dependent receptor & & & \\
\hline P4_HK & *21930 & histidine kinase & & & \\
\hline P5_isomerase & *21940 & 4-deoxy-L-threo-5-hexosulose-uronate ketol-isomerase & & & \\
\hline P6_dehydrogenase & *21950 & 2-deoxy-D-gluconate 3-dehydrogenase & & & \\
\hline $\mathrm{P} 7{ }^{-}$ & *21960 & conserved hypothetical protein & & & \\
\hline P8_GH2 & *21970 & beta-galactosidase $(\mathrm{GH} 2)$ & & & \\
\hline P9_lactonase & *21980 & 6-phosphogluconolactonase & & & \\
\hline P10_PLnc & *21990 & ulvan lyase (PLnc) & & & \\
\hline P11_S1_7 & *22000 & iduronate-2-sulfatase (S1_7) & & & \\
\hline P12_S1_8 & *22010 & arylsulfatase (S1_8) & & & \\
\hline $\mathrm{P} 13_{-}^{-} \mathrm{S} 1{ }_{-16}$ & *22020 & arylsulfatase (S1_16) & & & \\
\hline P14_S1_7 & *22030 & arylsulfatase (S1_7) & & & \\
\hline P15_GH2 & *22040 & glycoside hydrolase $(\mathrm{GH} 2)$ & & & \\
\hline P16_GH2 & *22050 & beta-galactosidase $(\mathrm{GH} 2)$ & & & \\
\hline P17_GH2 & *22060 & beta-galactosidase $(\mathrm{GH} 2)$ & & & \\
\hline P18_S1_7 & *22070 & arylsulfatase (S1_7) & & & \\
\hline P19_S1_27 & *22080 & sulfatase (S1_27) & & & \\
\hline P20_GH78 & *22090 & alpha-L-rhamnosidase $(\mathrm{GH} 78)$ & & & \\
\hline P21_mutarotase & *22100 & L-rhamnose mutarotase & & & \\
\hline P22 & *22110 & conserved hypothetical protein & & & \\
\hline P23 & *22120 & conserved hypothetical protein & & & \\
\hline P24_GH3 & *22130 & beta-glucosidase $(\mathrm{GH} 3)$ & & & \\
\hline P25_SusD & *22140 & SusD-like protein & & & \\
\hline P26_TBDR & *22150 & TonB-dependent receptor & & & \\
\hline P27_GH43 & *22160 & beta-xylosidase (GH43) & & & \\
\hline P28_GH78 & *22170 & alpha-L-rhamnosidase (GH78) & & & \\
\hline P29 & *22180 & conserved hypothetical protein & & & \\
\hline P30_PL28 & *22190 & ulvan lyase (PL28) & & & \\
\hline P31_GH39 & *22200 & glycoside hydrolase (GH39) & & & \\
\hline P32_S1_8 & *22210 & arylsulfatase (S1_8) & & & \\
\hline P33_GH105 & *22220 & glycoside hydrolase (GH105) & & & \\
\hline P34_GH3 & *22230 & beta-glucosidase $(\mathrm{GH} 3)$ & & & \\
\hline P35_oxidoreductase & *22240 & oxidoreductase & & & \\
\hline P36_GH78/S1_25 & *22250 & alpha-L-rhamnosidase/sulfatase (GH78/S1_25) & & & \\
\hline & *22260 & hypothetical protein & & & \\
\hline P38_SusD & *22270 & SusD-like protein & & & \\
\hline P39_TBDR & *22280 & TonB-dependent receptor & & & \\
\hline $\begin{array}{l}\text { Non-PUL H-encodec } \\
\text { (for ulvan-derived } \mathrm{m}\end{array}$ & $\begin{array}{l}\text { oteins } \\
\text { saccharide }\end{array}$ & ation) & & $g_{2}$ rati & \\
\hline Abbreviation & Locus tag & Functional annotation & fru & rha & ulv \\
\hline NP1_dehydrogenase & ${ }^{*} 21840$ & aldehyde dehydrogenase $\mathrm{A}$ & & & \\
\hline NP2_dehydrogenase & *21850 & L-lactate dehydrogenase & & & \\
\hline NP3_aldolase & *21860 & class II aldolase/adducin family protein & & & \\
\hline NP4_kinase & *21870 & pentulose/hexulose kinase & & & \\
\hline NP5_isomerase & *21880 & rhamnose isomerase ${ }^{a}$ & & & \\
\hline NP6_aldolase & *21890 & rhamnulose-1-phosphate aldolase & & & \\
\hline NP7_kinase & *160 & xylulose kinase & & & \\
\hline NP8_isomerase & *170 & xylose isomerase & & & \\
\hline NP9_oxidoreductase & ${ }^{*} 9410$ & D-mannonate oxidoreductase & & & \\
\hline NP10_dehydratase & *9420 & mannonate dehydratase & & & \\
\hline NP11_isomerase & *9430 & uronate isomerase & & & \\
\hline NP12_kinase & *9800 & 2-dehydro-3-deoxygluconate kinase & & & \\
\hline NP13_aldolase & *9820 & aldolase $^{b}$ & & & \\
\hline NP14_kinase & *11640 & 2-dehydro-3-deoxygluconate kinase & & & \\
\hline NP15_kinase & *16400 & 2-dehydro-3-deoxygluconate kinase & & & \\
\hline NP16_XylE & *180 & D-xylose transporter XylEc & & & \\
\hline NP17_ABC & *11090 & ABC transporter, ATP-binding protein & & & \\
\hline NP18_ABC & *25150 & ABC transporter, ATP-binding protein & & & \\
\hline NP19_ABC & *7480 & ABC transporter, ATP-binding protein & & & \\
\hline NP20_ABC & *12820 & ABC transporter, ATP-binding protein & & & \\
\hline $\begin{array}{l}\text { Proteins were numbe } \\
\text { and protein function }\end{array}$ & (P1 - P39: P & $\begin{array}{l}\text {-encoded proteins, NP1 - NP20: non-PUL H-encoded proteins) } \\
\text { case of glycoside hydrolases }(\mathrm{GH}) \text { and sulfatases (S), families }\end{array}$ & & & \\
\hline and subfamilies were & cified $^{21,22}$, e.c & 2 (family) or S1_7 (family and subfamily). "BN863_, e.g. "“21900" & 1.5 & & -7 \\
\hline refers to locus tag $B N$ & $21800 ;{ }^{\text {aide }}$ & d by BLAST against the Uniprot database, previously annotated & & & \\
\hline $\begin{array}{l}\text { as xylose isomerase } \\
\text { deoxyphosphoglucon } \\
\text { (Supplementary Data }\end{array}$ & $\begin{array}{l}\text { TIM barrel } \\
\text { aldolase, } \\
\text { 2), fru: fruct }\end{array}$ & $\begin{array}{l}\text { ain protein, } 4 \text {-hydroxy-2-oxoglutarate aldolase / 2-dehydro-3- } \\
\text { captured by subproteome analysis of ulvan-grown cells } \\
\text { ha: rhamnose, ulv: ulvan }\end{array}$ & & & \\
\hline
\end{tabular}


Ulvan

$\mathrm{OO}_{\mathrm{O}_{3} \mathrm{SO}}$

$\Theta_{\mathrm{OOC}}$

Rha

DKI
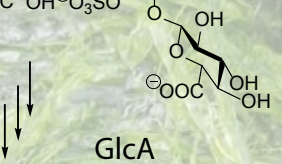

GICA

Xyl

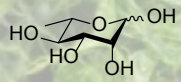

$\Theta_{\mathrm{OOC}}$

$\mathrm{HO}+\mathrm{HO} \mathrm{OH}$
HOL 
a

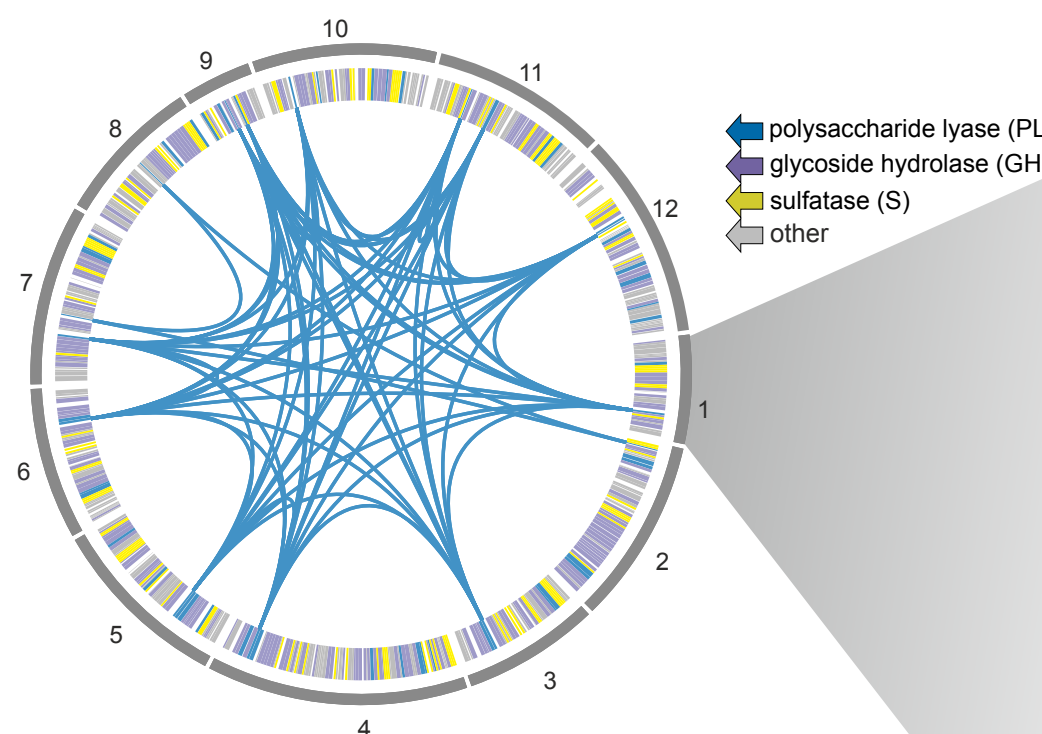

C

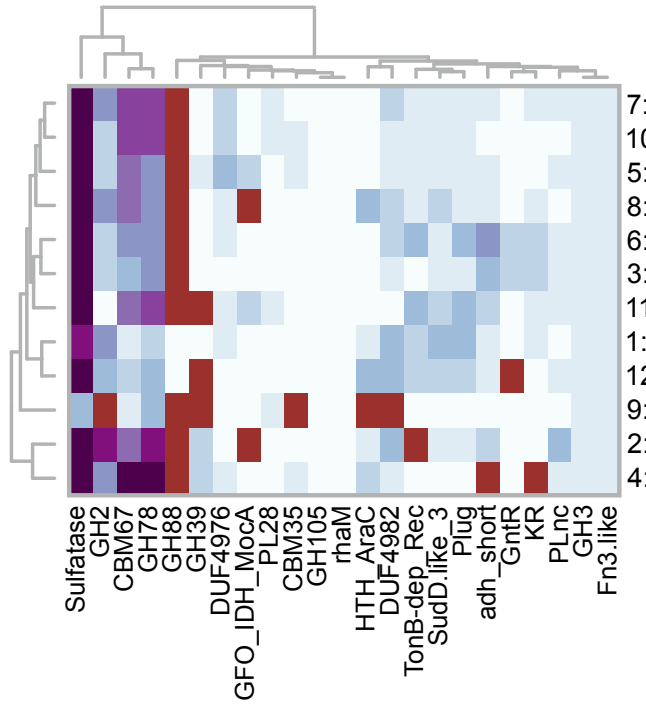

b

7: Tamlana sp. UJ94

5: Polaribacter sp. WD7

8: Wenyingzhuangia fucanilytica

6: Polaribacter sp. KT 15

3: Polaribacter sp. BM9

11: Cellulophaga tyrosinoxydans

1: Formosa agariphila KMM 3901

12: Flammeovirga pacifica

: Nonlabens sediminis

2: Labilibacter marinus

4: Polaribacter sp. ZY113

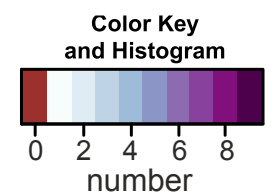

10: Algibacter pectinivorans
P1_GH88
P2_SusD
P3_TBDR
P4_HK

P5 isomerase

P6_dehydrogenase

P7

P8_GH2

P9_lactonase

P10_PLnc

P11_S1_7

$\mathrm{P} 12 \mathrm{~S} 18 \mathrm{C}$

P13_S1_16

P14_S1_7

P15_GH 2

P16_GH2

P17_GH2

P18_S1_7

P19 S1_27

P20_GH78

P21_mutarotase

P22

P23

P24_GH3

P25_SusD

P26_TBDR

P27_GH43

P28_GH78

P29

P30_PL28

P31_GH39

P32_S1_8

P33_GH105

$\mathrm{P} 34$ _GH3

P35_oxidoreductase P36_GH78/S1_25

P37

P38_SusD

P39_TBDR 1

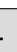

11

2

$\log 2$

rhamnose ulvan 

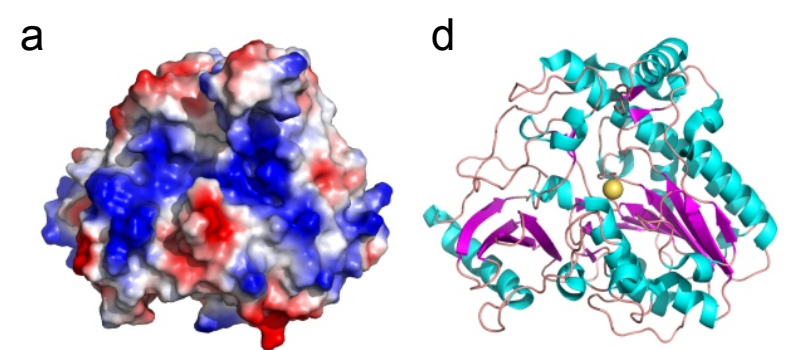

g
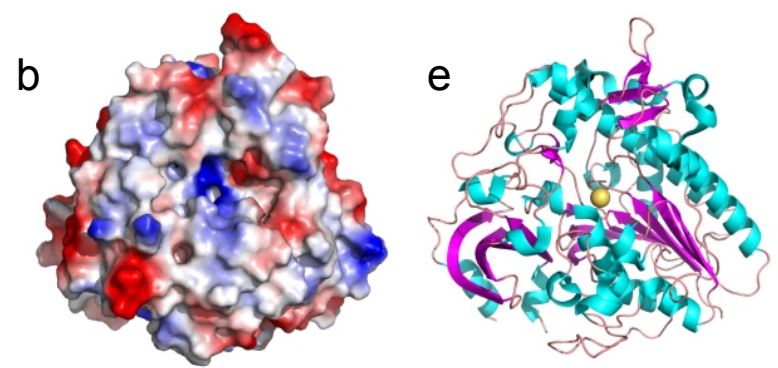

h
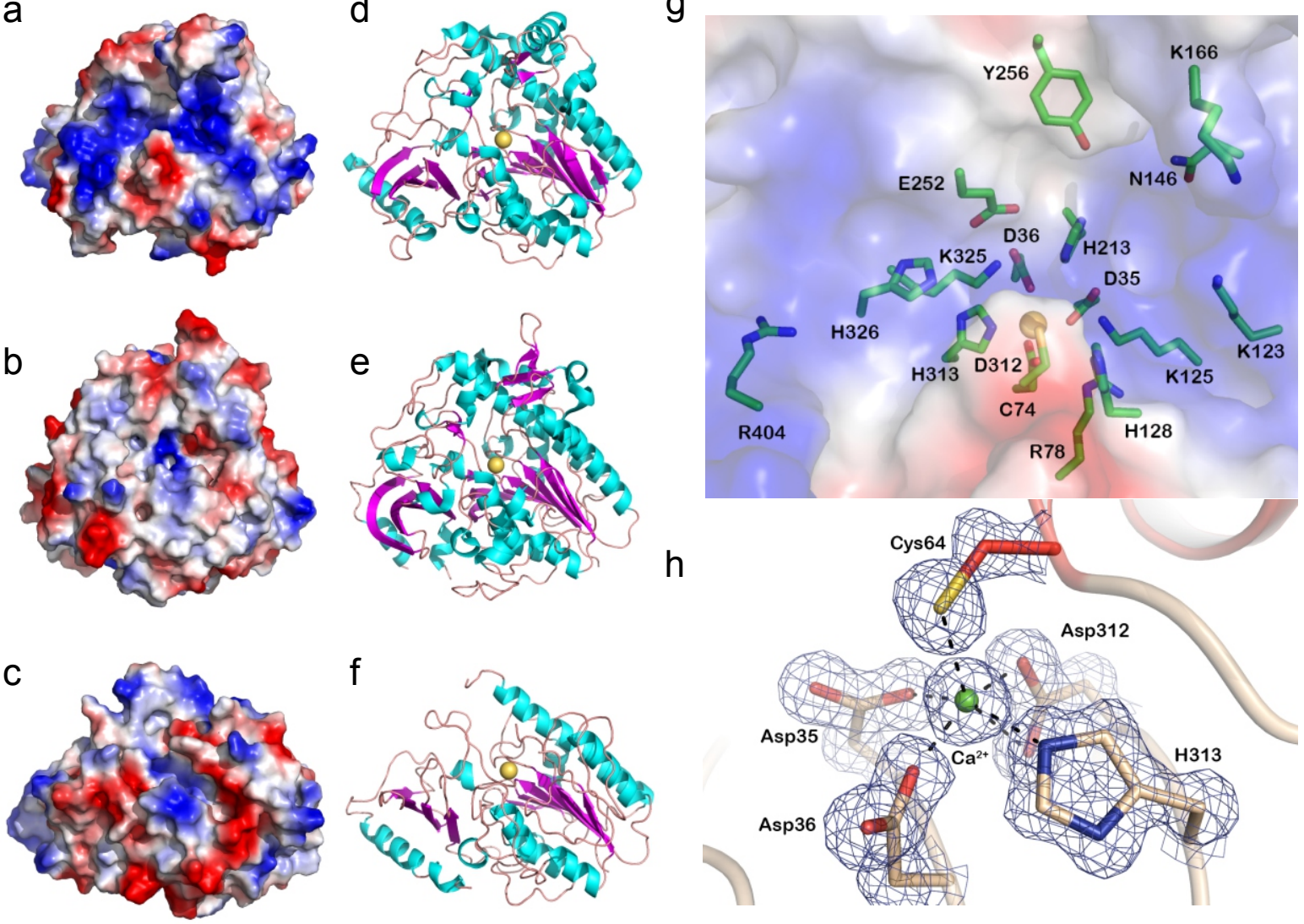


$$
\text { I }
$$


a

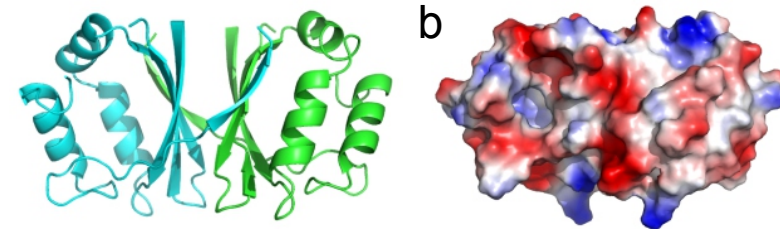

C

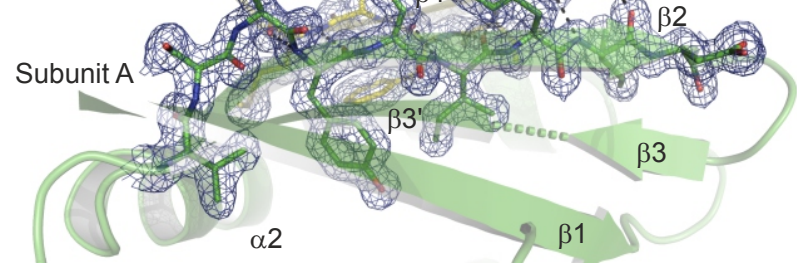

d

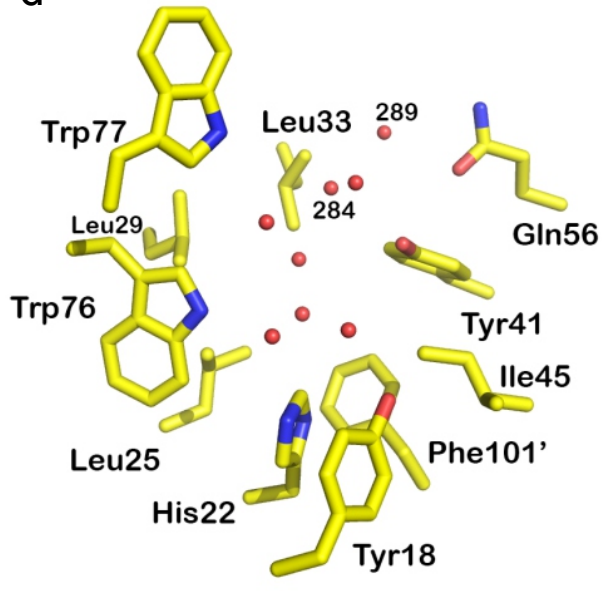

e

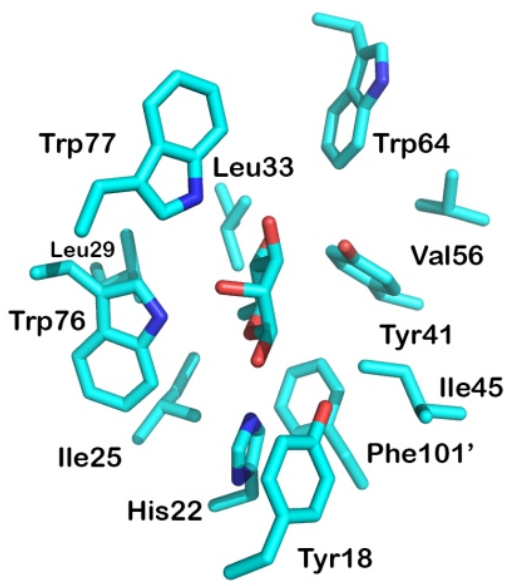




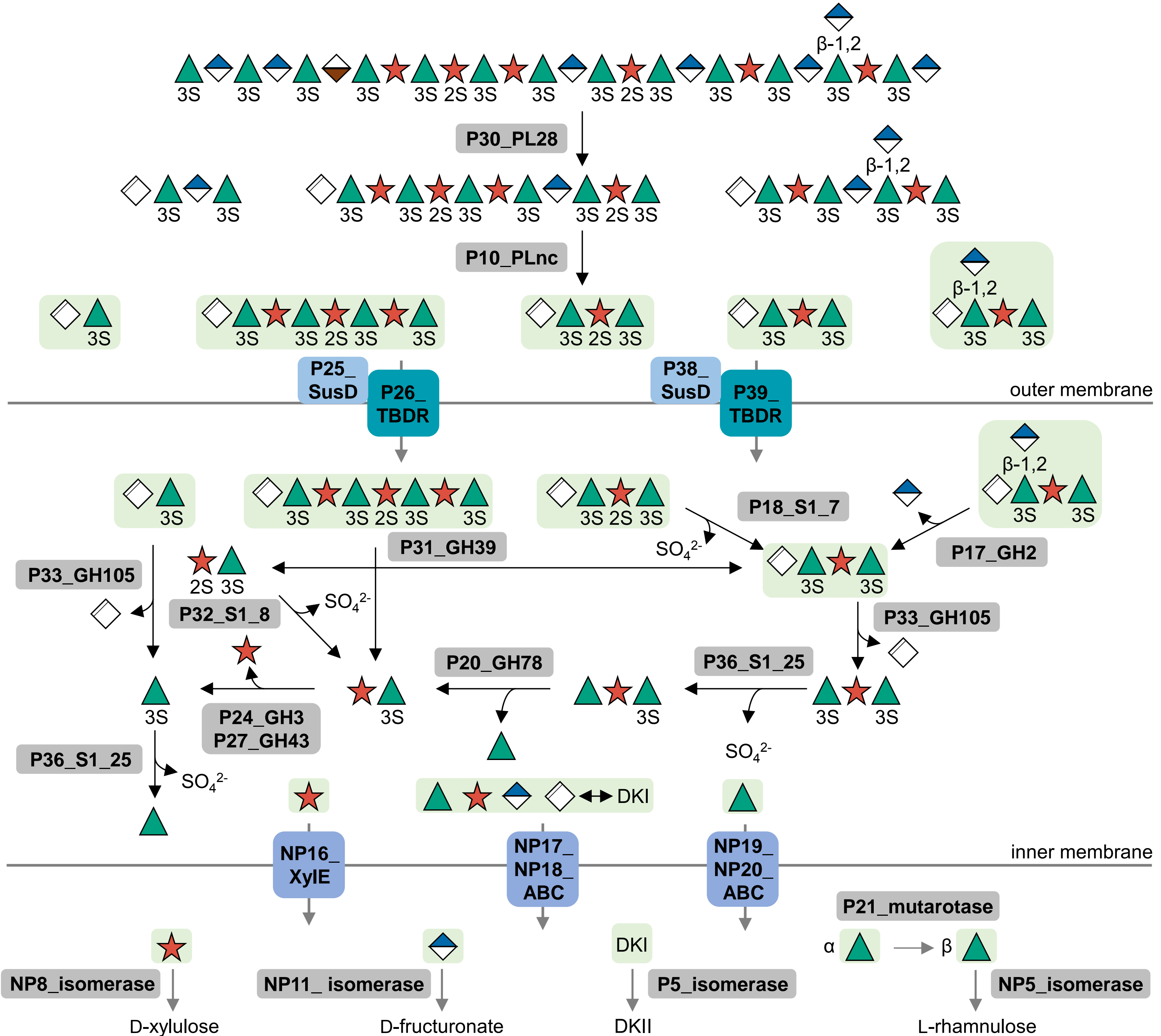

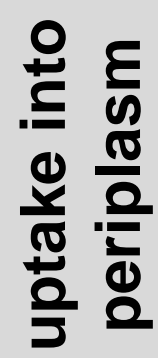

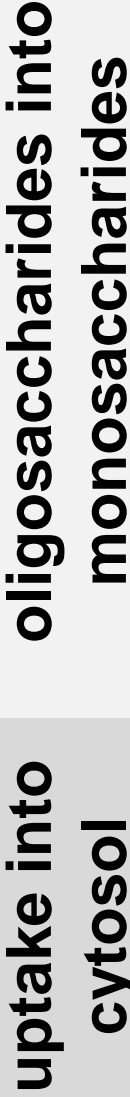

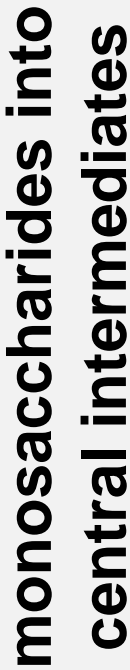

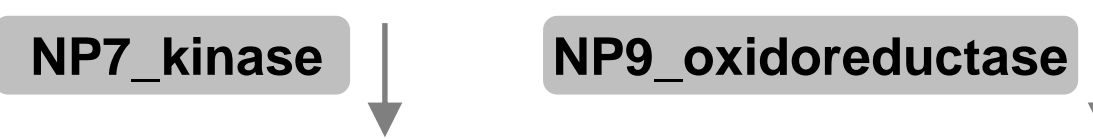

D-xylulose-5P

D-mannonate

P6_dehydrogenase

NP4_kinase

pentose phosphate

pathway

NP10_dehydratase

D-glyceraldehyde-3P

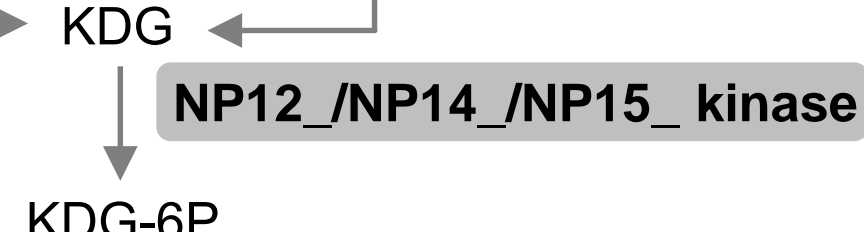

L-lactaldehyde

dihydroxyacetone-P

\section{NP13_aldolase}

D-glyceraldehyde-3P

+ pyruvate

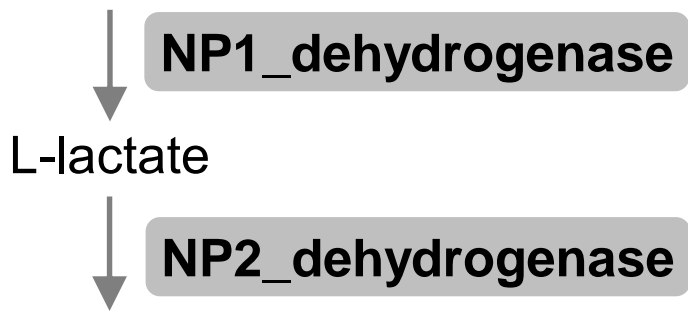

pyruvate

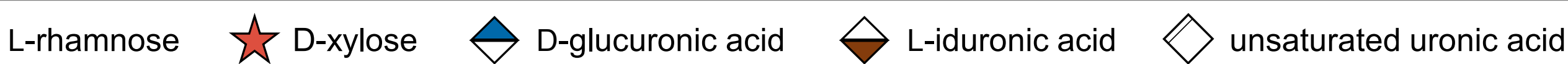

